Prepared in cooperation with the

New Jersey Department of Environmental Protection

Organic Compounds, Trace Elements, Suspended Sediment, and Field Characteristics at the Heads-of-Tide of the Raritan, Passaic, Hackensack, Rahway, and Elizabeth Rivers, New Jersey, 2000-03

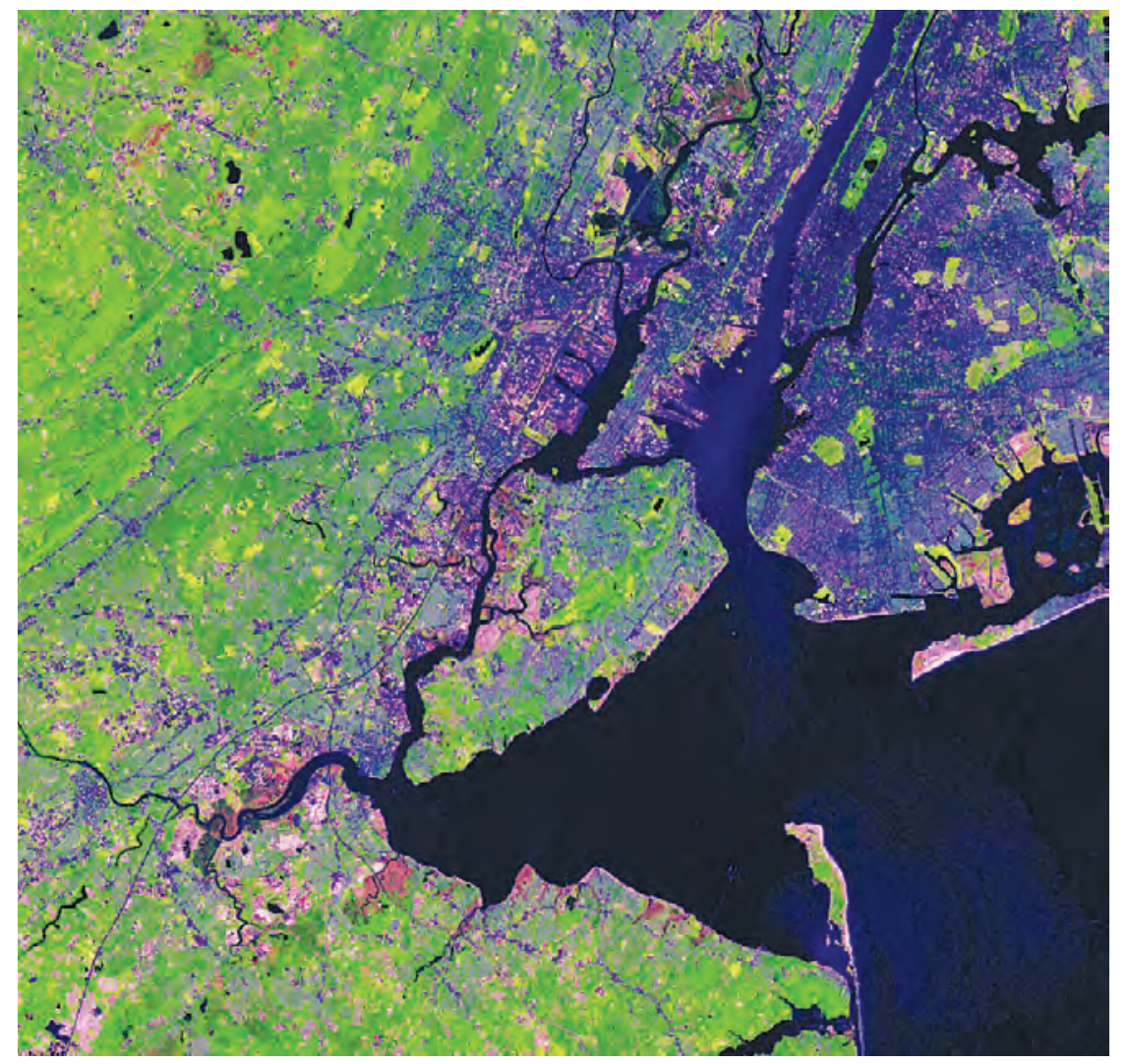

Data Series 123 


\section{Organic Compounds, Trace Elements, Suspended Sediment, and Field \\ Characteristics at the Heads-of-Tide of the Raritan, Passaic, Hackensack, Rahway, and Elizabeth Rivers, New Jersey, 2000-03}

By Jennifer L. Bonin and Timothy P. Wilson

Prepared in cooperation with the

New Jersey Department of Environmental Protection

Data Series 123 


\section{U.S. Department of the Interior \\ Dirk Kempthorne, Secretary \\ U.S. Geological Survey \\ P. Patrick Leahy, Acting Director}

U.S. Geological Survey, Reston, Virginia: 2006

For product and ordering information:

World Wide Web: http://www.usgs.gov/pubprod

Telephone: 1-888-ASK-USGS

For more information on the USGS--the Federal source for science about the Earth, its natural and living resources, natural hazards, and the environment:

World Wide Web: http://www.usgs.gov

Telephone: 1-888-ASK-USGS

Any use of trade, product, or firm names is for descriptive purposes only and does not imply endorsement by the U.S. Government.

Although this report is in the public domain, permission must be secured from the individual copyright owners to reproduce any copyrighted materials contained within this report. 


\section{Contents}

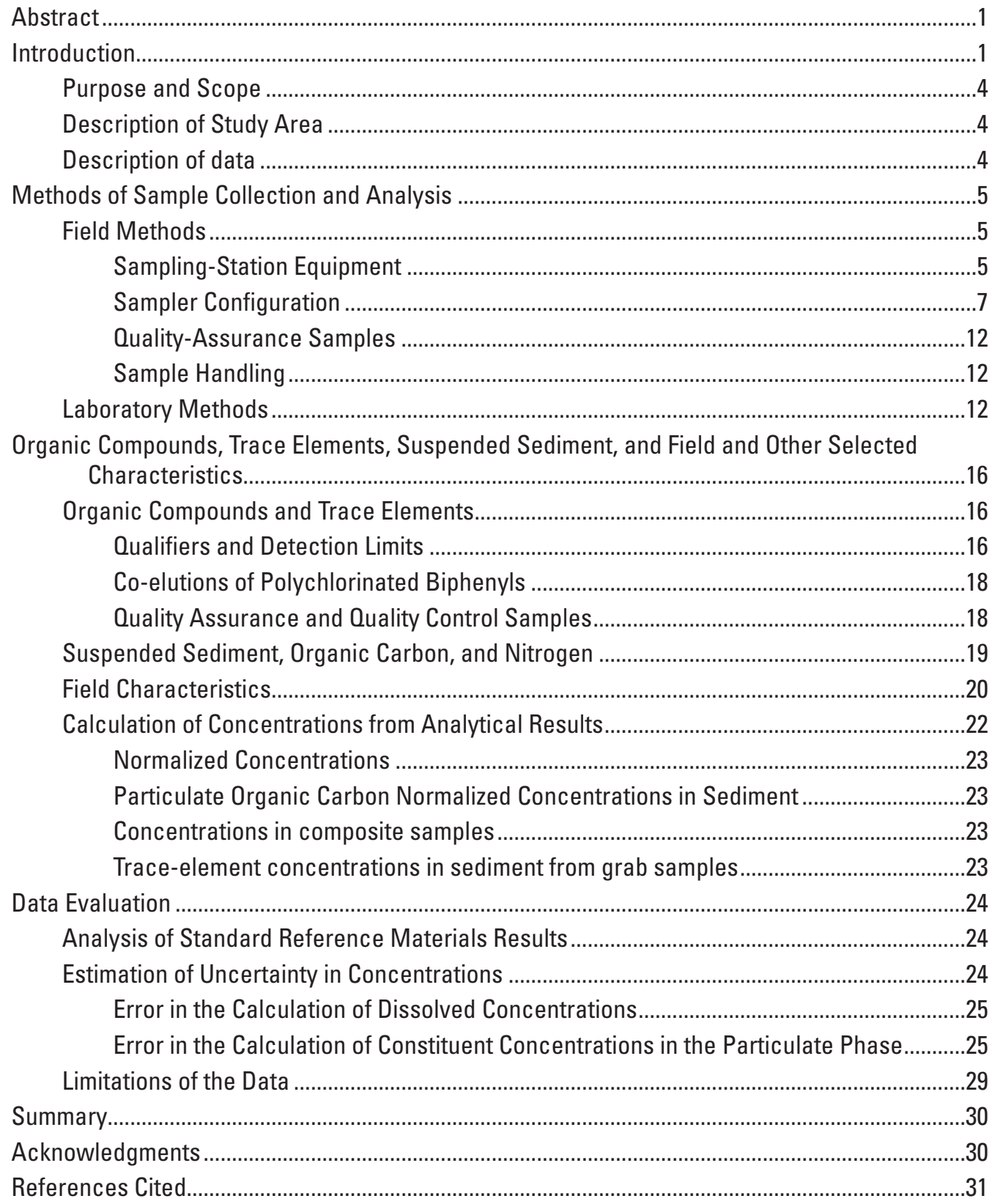




\section{Figures}

1-2. Maps showing-

1. Location of surface-water sampling sites on the Raritan, Passaic,

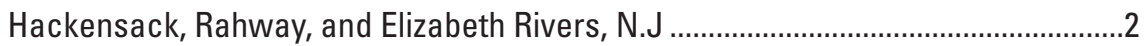

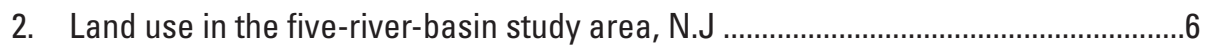

3. Water-quality sampling station on the Passaic River at Little Falls, N.J............................

4. Schematic diagram showing the configuration of the automatic samplers ......................

5. A Trace Organic Platform Sampler (TOPS) used to collect water samples .....................10

6. Schematic diagram of a Trace Organic Platform Sampler (TOPS) ................................11

\section{Tables}

1. Description of the surface-water sampling sites on the Raritan, Passaic, Hackensack, Rahway, and Elizabeth Rivers, New Jersey.

2. Hydrologic and land-use attributes at selected discharge gages in the Raritan, Passaic, Hackensack, Rahway, and Elizabeth River basins, New Jersey.

3. Description of sample types collected from, and equipment used in, the Raritan, Passaic, Hackensack, Rahway and Elizabeth Rivers, New Jersey.

4. Sample identifiers, collection dates, and sites for samples collected from the Raritan, Passaic, Hackensack, Rahway and Elizabeth Rivers, New Jersey

5. Carbon-13 and chlorine-37 labeled field surrogates used with the XAD-resin columns

6. Description of blank samples used for quality assurance.

7. Field characteristics measured during sample collection at sites on the Raritan, Passaic, Hackensack, Rahway, and Elizabeth Rivers, New Jersey. CD

8. Constituents in sediment and water samples collected from the Raritan, Passaic, Hackensack, Rahway, and Elizabeth Rivers, New Jersey...............................................14

9. Methods used for analysis of water and sediment samples .........................................16

10. Results of quality-assurance and quality-control sample analyses .................................

11. Results of National Institute of Standards and Technology/National Oceanic and Atmospheric Administration quality-assurance sample analyses.

12. Results of $X A D-2$ resin quality-control sample analyses.................................................

13. Mass of polychlorinated biphenyl congeners recovered in samples of suspended sediment and water from the Raritan, Passaic, Hackensack, Rahway, and Elizabeth Rivers, New Jersey

14. Mass of dioxins and furans recovered in suspended sediment filtered from water samples collected from the Raritan, Passaic, Hackensack, Rahway, and Elizabeth Rivers, New Jersey

15. Mass or concentration of polycyclic aromatic hydrocarbons recovered from samples of suspended sediment and water collected from the Raritan, Passaic, Hackensack, Rahway, and Elizabeth Rivers, New Jersey.

16. Mass of organochlorine pesticides recovered in samples of suspended sediment and water collected from the Raritan, Passaic, Hackensack, Rahway, and Elizabeth Rivers, New Jersey 
17. Concentrations of trace elements in samples of suspended sediment and water collected from the Raritan, Passaic, Hackensack, Rahway, and Elizabeth Rivers, New Jersey... CD

18. Description of data qualifiers included in analytical results...........................................17

19. Ranges of reported estimated detection limits (EDLs) and method detection limits (MDLs) for trace elements and organic compounds in field and equipment blanks ......18

20. Description of co-eluting polychlorinated biphenyl congener sets...............................19

21. Description of standard reference materials used in the quality assurance/quality

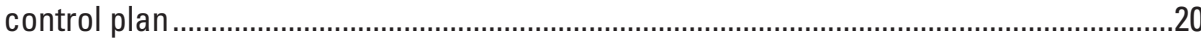

22. Summary of quality assurance and quality control analyses ........................................21

23. Concentrations of suspended sediment, dissolved and particulate organic carbon, and other measured constituents in samples collected from the Raritan, Passaic, Hackensack, Rahway, and Elizabeth Rivers, New Jersey.

24. Concentrations of suspended sediment, dissolved and particulate organic carbon, and other measured constituents in samples collected from the Raritan, Passaic, Rahway, and Elizabeth Rivers, New Jersey

25. Location of precipitation stations in New Jersey river basins. ...................................22

26. Means and variances for polycyclic aromatic hydrocarbons measured in standard reference materials.

27. Means and variances for polychlorinated biphenyls measured in standard reference materials.

28. Means and variances for pesticides measured in standard reference materials ..........28 


\section{Conversion Factors and Abbreviated Water-Quality Units}

\begin{tabular}{|c|c|c|}
\hline Multiply & By & To obtain \\
\hline \multicolumn{3}{|c|}{ Length } \\
\hline millimeter $(\mathrm{mm})$ & 0.03937 & inch (in) \\
\hline centimeter $(\mathrm{cm})$ & 0.3937 & inch (in) \\
\hline meter $(\mathrm{m})$ & 3.281 & foot $(\mathrm{ft})$ \\
\hline kilometer $(\mathrm{km})$ & 0.6214 & mile (mi) \\
\hline \multicolumn{3}{|c|}{ Area } \\
\hline square meter $\left(\mathrm{m}^{2}\right)$ & 0.0002471 & acre \\
\hline square kilometer $\left(\mathrm{km}^{2}\right)$ & 0.3861 & square mile $\left(\mathrm{mi}^{2}\right)$ \\
\hline \multicolumn{3}{|c|}{ Volume } \\
\hline liter $(\mathrm{L})$ & 3.785 & gallon (gal) \\
\hline milliliter (mL) & 3,785 & gallon (gal) \\
\hline cubic meter per second $\left(\mathrm{m}^{3} / \mathrm{s}\right)$ & 35.31 & cubic feet per second $\left(\mathrm{ft}^{3} / \mathrm{s}\right)$ \\
\hline cubic meter per second $\left(\mathrm{m}^{3} / \mathrm{s}\right)$ & 15,850 & gallons per minute (gal/min) \\
\hline \multicolumn{3}{|c|}{ Mass } \\
\hline gram $(\mathrm{g})$ & 0.03527 & ounce, avoirdupois (oz) \\
\hline
\end{tabular}

Vertical coordinate information is referenced to the National Geodetic Vertical Datum of 1929 (NGVD of 1929).

Horizontal coordinate information is referenced to the North American Datum of 1983 (NAD83).

Altitude, as used in this report, refers to distance above the vertical datum.

\begin{tabular}{ll}
\hline & Water quality abbreviations \\
\hline PCB & Polychlorinated biphenyl \\
PAH & Polycyclic aromatic hydrocarbons \\
XAD & Chemical exchange resin \\
SS & Suspended sediment \\
POC & Particulate organic carbon \\
DOC & Dissolved organic carbon \\
$\mu \mathrm{g}$ & microgram \\
ng & nanogram \\
pg & picogram \\
\hline
\end{tabular}




\title{
Organic Compounds, Trace Elements, Suspended Sediment, and Field Characteristics at the Heads-of- Tide of the Raritan, Passaic, Hackensack, Rahway, and Elizabeth Rivers, New Jersey, 2000-03
}

\author{
By Jennifer L. Bonin and Timothy P. Wilson
}

\section{Abstract}

Concentrations of suspended sediment, particulate and dissolved organic carbon, trace elements, and organic compounds were measured in samples from the heads-of-tide of the five tributaries to the Newark and Raritan Bays during June 2000 to June 2003. The samples were collected as part of the New Jersey Department of Environmental Protection Toxics Reduction Workplan/Contaminant Assessment Reduction Program. Samples of streamwater were collected at waterquality sampling stations constructed near U.S. Geological Survey gaging stations on the Raritan, Passaic, Hackensack, Rahway, and Elizabeth Rivers. Sampling was conducted during base-flow conditions and storms. Constituent concentrations were measured to determine the water quality and to calculate the load of sediment and contaminants contributed to the bays from upstream sources.

Water samples were analyzed for suspended sediment, dissolved organic carbon, particulate organic carbon, and specific conductance. Samples of suspended sediment and water were analyzed for 98 distinct polychlorinated biphenyl congeners, 7 dioxins, 10 furans, 27 pesticides, 26 polycyclic aromatic hydrocarbons, and the trace elements cadmium, lead, mercury, and methyl-mercury. Measurements of ultra-low concentrations of organic compounds in sediment and water were obtained by collecting 1 to 3 grams of suspended sediment on glass fiber filters and by passing at least 20 liters of filtered water through XAD-2 resin. The extracted sediment and XAD-2 resin were analyzed for organic compounds by high- and low-resolution gas chromatography mass-spectrometry that uses isotope dilution procedures. Trace elements in filtered and unfiltered samples were analyzed for cadmium, lead, mercury, and methyl-mercury by inductively coupled charged plasma and mass-spectrometry.

All constituent concentrations are raw data. Interpretation of the data will be completed in the second phase of the study.

\section{Introduction}

The estuaries of the Newark and Raritan Bays in New Jersey and the Hudson River estuary in New York have long been major shipping ports and manufacturing areas in northeastern United States. Five major tributaries discharge to New Jersey estuaries and bays-- the Raritan, Passaic, Hackensack, Rahway, and Elizabeth Rivers (fig. 1). Because sediment is deposited by these rivers, the bays need to be dredged continually to maintain their use as shipping ports. Discharges of industrial and waste-related chemicals associated with the extensive urbanization and industrialization in these river basins have resulted in the contamination of the river water and sediment. Inputs from point and non-point sources in the basins and riverine storage of previously released chemicals supply contaminants to the sediment in the estuaries and harbors. The chemicals associated with the sediment pose significant threats to ecologic and human health. When removed by dredging, the contaminated sediment is difficult and expensive to treat and dispose of (New York/New Jersey Harbor Estuary Program Comprehensive Conservation and Management Plan, 1996).

In an attempt to restore these estuaries and to reduce the need for continual dredging of contaminated sediment from the ports, the States of New Jersey and New York began a cooperative research project to evaluate the loads of toxic chemicals and sediment to the Newark and Raritan Bays, and to the Hudson River estuary (New Jersey Department of Environmental Protection, 2001). This program, the Contaminant Assessment and Reduction Program (CARP), was established to characterize the types and concentrations of contaminants in the rivers and to prioritize the riverine inputs by determining loads of the constituents and sediment so that future efforts can focus on remediation of the sources of contamination.

The U.S. Geological Survey (USGS) has monitored water discharge and water-quality constituents, such as concentrations of suspended sediment, in New Jersey tributaries for many years (table 1). Buxton and others (1998) compiled 


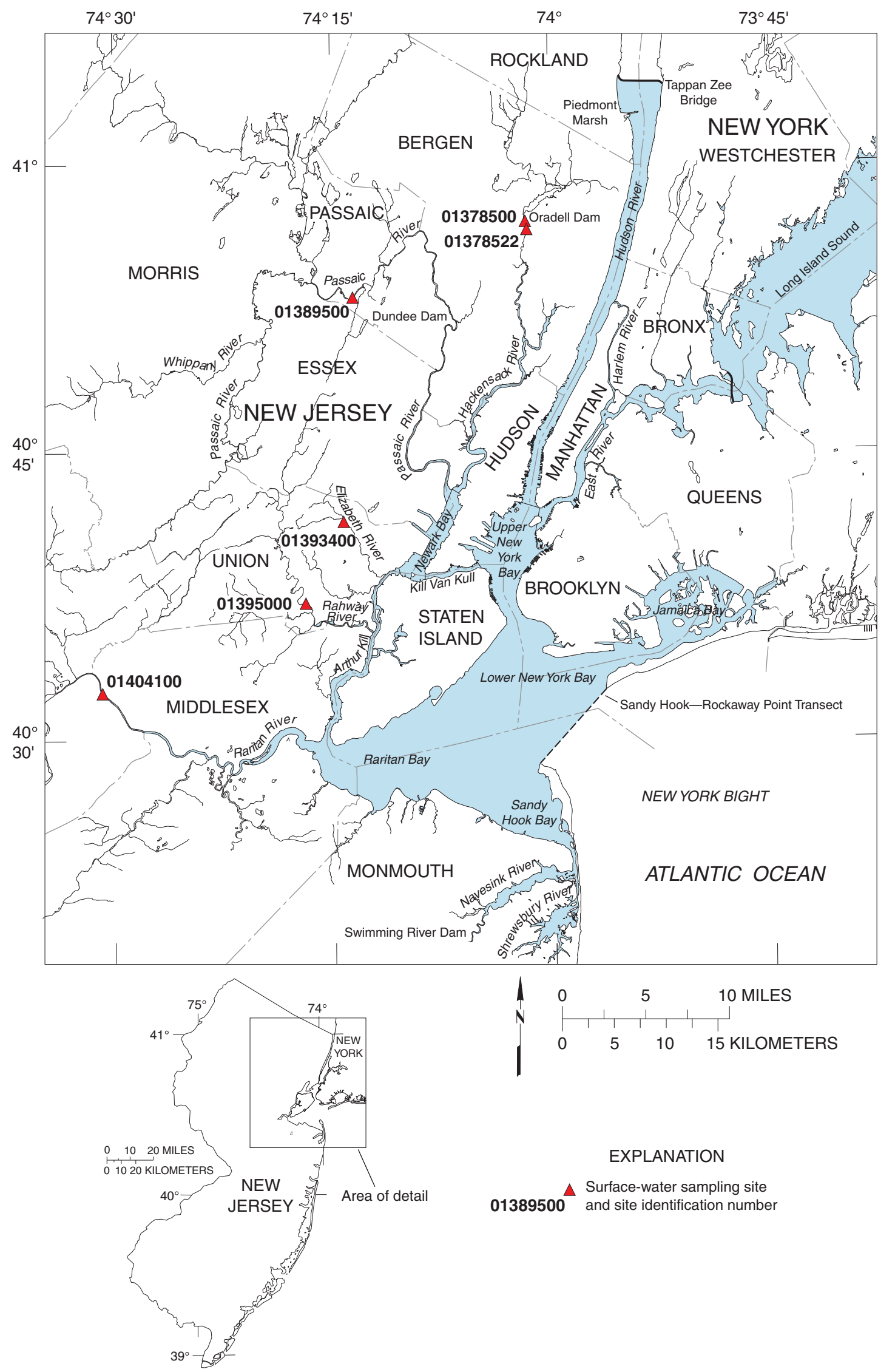

Figure 1. Location of surface-water sampling sites on the Raritan, Passaic, Hackensack, Rahway, and Elizabeth Rivers, N.J. (From: New York/New Jersey Harbor Estuary Final Comprehensive Conservation and Management Plan, March 1996.) 
Table 1. Description of the surface-water sampling sites on the Raritan, Passaic, Hackensack, Rahway, and Elizabeth Rivers, New Jersey.

[USGS, U.S. Geological Survey; NGVD of 29, National Geodetic Vertical Datum of 1929; N.J., New Jersey; NA, not applicable; Horizontal datum is North American Datum of 1983]

\begin{tabular}{|c|c|c|c|c|c|c|c|c|}
\hline $\begin{array}{l}\text { USGS sampling } \\
\text { site } \\
\text { identification } \\
\text { number }\end{array}$ & $\begin{array}{l}\text { Sampling site } \\
\text { identifier }\end{array}$ & Sampling site name & $\begin{array}{l}\text { Sampling site } \\
\text { type }\end{array}$ & $\begin{array}{l}\text { Sampling site } \\
\text { latitude } \\
\text { (degrees, } \\
\text { minutes, and } \\
\text { seconds) }\end{array}$ & $\begin{array}{l}\text { Sampling site } \\
\text { longitude } \\
\text { (degrees, } \\
\text { minutes, and } \\
\text { seconds) }\end{array}$ & $\begin{array}{l}\text { USGS gaging } \\
\text { station } \\
\text { identification } \\
\text { number }\end{array}$ & $\begin{array}{c}\text { USGS gaging } \\
\text { station datum } \\
\text { (feet above } \\
\text { NGVD of 29) }\end{array}$ & $\begin{array}{l}\text { Position of sampling } \\
\text { site in relation to } \\
\text { gaging station }\end{array}$ \\
\hline 01389500 & PASSAICHOT & $\begin{array}{l}\text { Passaic River at } \\
\text { Little Falls, N.J. }\end{array}$ & $\begin{array}{l}\text { Sampling and } \\
\text { stream gage }\end{array}$ & $40^{\circ} 53^{\prime} 06.57^{\prime \prime}$ & $74^{\circ} 13^{\prime} 32.23^{\prime \prime}$ & 01389500 & 120.00 & $\begin{array}{l}\text { Immediately adjacent } \\
\text { to the gaging station }\end{array}$ \\
\hline 01378500 & HACKENHOT & $\begin{array}{r}\text { Hackensack River at } \\
\text { New Milford, N.J. }\end{array}$ & $\begin{array}{l}\text { Sampling (fresh- } \\
\text { water) and } \\
\text { stream gage }\end{array}$ & $40^{\circ} 56^{\prime} 54^{\prime \prime}$ & $74^{\circ} 01^{\prime} 37^{\prime \prime}$ & 01378500 & 6.25 & $\begin{array}{l}\text { Immediately adjacent } \\
\text { to the gaging station }\end{array}$ \\
\hline 01378522 & HAC4 & $\begin{array}{l}\text { Hackensack River at } \\
\text { Oradell, N.J. }\end{array}$ & Sampling (tidal) & $40^{\circ} 56^{\prime} 36.2^{\prime \prime}$ & $74^{\circ} 01^{\prime} 29.65^{\prime \prime}$ & 01378500 & 6.25 & $\begin{array}{l}0.5 \text { miles downstream } \\
\text { from the gaging } \\
\text { station }\end{array}$ \\
\hline 01404100 & RARITANHOT & $\begin{array}{l}\text { Raritan River near } \\
\text { South Bound } \\
\text { Brook, N.J. }\end{array}$ & Sampling & $40^{\circ} 32^{\prime} 26.04^{\prime \prime}$ & $74^{\circ} 30^{\prime} 49.71^{\prime \prime}$ & 01403060 & 0.00 & $\begin{array}{l}0.75 \text { miles downstream } \\
\text { from the gaging } \\
\text { station }\end{array}$ \\
\hline 01395000 & RAHWAYHOT & $\begin{array}{c}\text { Rahway River at } \\
\text { Rahway, N.J. }\end{array}$ & $\begin{array}{l}\text { Sampling and } \\
\text { stream gage }\end{array}$ & $40^{\circ} 37^{\prime} 07.48^{\prime \prime}$ & $74^{\circ} 16^{\prime} 53.20^{\prime \prime}$ & 01395000 & 8.77 & $\begin{array}{l}0.1 \text { miles downstream } \\
\text { from the gaging } \\
\text { station }\end{array}$ \\
\hline 01393400 & ELIZABHOT & $\begin{array}{c}\text { Elizabeth River at } \\
\text { Hillside, N.J. }\end{array}$ & Sampling & $40^{\circ} 41^{\prime} 20.95^{\prime \prime}$ & $74^{\circ} 14^{\prime} 16.13^{\prime \prime}$ & 01393450 & 0.00 & $\begin{array}{l}0.5 \text { miles upstream } \\
\text { from the gaging } \\
\text { station }\end{array}$ \\
\hline
\end{tabular}


previously collected data to evaluate trends between stream discharge and sediment, and constituent concentrations, in grab samples. The earlier sampling programs did not measure trace organic and inorganic constituents in the rivers nor did the earlier data provide the information needed to calculate sediment and carbon loads.

The USGS, in cooperation with the New Jersey Department of Environmental Protection (NJDEP), conducted a study as part of the CARP to determine which constituents were present in water that moved across the head-of-tide, which is the uppermost point in the tributary where water levels are affected by daily oceanic tides, of each of the five major tributaries to the estuary system. (The New Jersey study, referred to as NJ-CARP, was carried out by the USGS New Jersey Water Science Center.) Analyses were conducted to determine the concentrations of the constituents in water and sediment and to calculate the fluxes of the constituents in water and sediment into the system from above the heads-oftide. Concurrent with the sampling reported here and in conjunction with the CARP, water samples were collected at many locations within the estuary and bays and at many sewagetreatment facilities and stormwater outfalls within the estuary system. Samples were analyzed for polychlorinated biphenyl congeners, dioxins, furans, pesticides, polycyclic aromatic hydrocarbons, and trace elements in an effort to characterize the inputs, storage components, and outputs to the harbor system as a whole (New Jersey Department of Environmental Protection, 2001). In 1998, the New York State Department of Environment and Conservation undertook a similar program in the Hudson River basin (New York State Department of Environment and Conservation, 1998).

The results of analyses for the constituents noted above are reported as raw data. A second phase of this study focuses on the interpretation of the constituent data.

\section{Purpose and Scope}

The purpose of this report is to describe sample collection techniques, analytical methods, and quality-assurance procedures, and to present data on organic compounds, organic carbon, trace elements, and suspended sediment in samples collected at six sampling sites on the 5 major rivers in New Jersey that discharge to the New York-New Jersey Harbor Estuary-- the Raritan, Passaic, Hackensack, Rahway, and Elizabeth Rivers-- from June 2000 to June 2003.

\section{Description of Study Area}

The study area consists of the Hackensack and Passaic Rivers, which flow into Newark Bay; the Elizabeth and Rahway Rivers, which flow into the Arthur Kill; and the Raritan River which flows into Raritan Bay (fig. 1; table 1). The Passaic and Raritan Rivers drain large basins of more than $700 \mathrm{mi}^{2}$. The flow in these rivers typically remains elevated for several days after precipitation occurs. The Hackensack, Rahway, and Elizabeth Rivers drain much smaller basins of less than $100 \mathrm{mi}^{2}$ that consequently have small discharges. Flow in these rivers typically remains elevated for less than a day after precipitation ends (table 2). Flow on all of these rivers is affected by flow-control and diversion structures, such as dams and reservoirs, and by inputs from sewers and other outfalls, all of which greatly affect the responses of these rivers to precipitation.

Land use in these river basins, as determined from the NJDEP Geographic Information Systems Database for the part of the basin upstream from the sampling sites, provides useful insight into the characteristics of these basins. All of the basins are classified mainly as urban, although about 20 percent of the land use in the Raritan River basin is agricultural or lowdensity rural housing. In the Passaic and Raritan River basins, 36 and 27 percent, respectively, of the land is forested. The high degree of urbanization is reflected in the large number of dischargers and waste-treatment plants that are permitted to release effluent into the surface-water system in each basin (fig. 2). The number of stormwater discharge sites in each basin is unknown but is likely to be much greater than the number of permitted discharge sites.

\section{Description of data}

In this study, the concentrations of suspended sediment, persistent trace organic compounds, and trace elements were measured in samples from the five rivers during base flow and stormflow from June 2000 to June 2003 (tables 3 and 4). The constituents of concern were identified in the New York/New Jersey Harbor Estuary Program Final Comprehensive Conservation and Management Plan (New York/New Jersey Harbor Estuary Program, 1996). The sample types are suspended sediment collected on filters, dissolved organic compounds collected on exchange XAD-2 resin, composite whole-water samples, and discrete grab whole-water samples (table 3). The data on organic compounds reported here are the masses associated with the dissolved and particulate phases of organic compounds recovered in flow-weighted composite samples that were collected with automatic samplers. A flow-weighted composite sample is produced by processing set volumes (aliquots) of river water that were collected each time a specified volume of river water passed the sampling station. Analysis of the composite sample produces an average constituent concentration that represents the entire storm or base-flow interval. In contrast, concentrations of suspended sediment (SS) and dissolved (DOC) and particulate (POC) organic carbon were measured in individual (discrete) samples collected each time the specified river volume passed. This allowed the variation in concentrations of these analytes during storms to be observed, and the geometric mean of the concentrations of SS, POC, and DOC in these discrete sample concentrations represents the flow-weighted average concentration in the river. Concentrations of trace elements were measured in grab 
Table 2. Hydrologic and land-use attributes at selected discharge gages in the Raritan, Passaic, Hackensack, Rahway, and Elizabeth River basins, New Jersey.

[Land-use data were obtained from the New Jersey Department of Environmental Protection (NJDEP) Geographic Information Systems database; $\mathrm{ft}^{3} / \mathrm{s}$, cubic feet per second; , approximately; Hydrologic data are from Reed and others, 2004.]

\begin{tabular}{|c|c|c|c|c|c|}
\hline Attribute & Raritan & Passaic & Hackensack & Rahway & Elizabeth \\
\hline USGS gaging station identification number & 01403060 & 013895000 & 01378500 & 01395000 & 01393450 \\
\hline Drainage area, in square miles & 785 & 762 & 113 & 40.9 & 16.9 \\
\hline Period of record & 1944-present & 1897-present & 1921-present & $\begin{array}{l}\text { 1908-1915, } \\
\text { 1921-present }\end{array}$ & 1921-present \\
\hline Mean annual flow, $\mathrm{ft}^{3} / \mathrm{s}$ & 1,189 & 1,132 & 90.4 & 49.1 & 25.9 \\
\hline 10-percent exceedance flow, $\mathrm{ft}^{3} / \mathrm{s}$ & 2,580 & 2,740 & 264 & 100 & 51 \\
\hline 50-percent exceedance flow, $\mathrm{ft}^{3} / \mathrm{s}$ & 615 & 625 & 15 & 19 & 11 \\
\hline 90-percent exceedance flow, $\mathrm{ft}^{3} / \mathrm{s}$ & 165 & 118 & 0.00 & 3.6 & 5.6 \\
\hline Number of reservoirs & 2 & 9 & 4 & 3 & 0 \\
\hline Number of water diversions in basin & 5 & $\sim 10$ & 7 & 3 & 1 \\
\hline \multicolumn{6}{|l|}{ Land-use, in percent of area in basin: } \\
\hline Agricultural & 26.51 & 1.66 & 0.97 & 0.16 & 0.07 \\
\hline Urban & 29.58 & 33.27 & 69.37 & 79.28 & 92.07 \\
\hline Barren & 1.41 & 0.98 & 0.26 & 0.58 & 0.10 \\
\hline Forested & 30.26 & 48.85 & 20.46 & 16.45 & 4.79 \\
\hline Water & 1.68 & 4.34 & 5.10 & 1.02 & 0.26 \\
\hline Wetlands & 10.57 & 10.90 & 3.84 & 2.50 & 2.71 \\
\hline Number of NJDEP permitted discharge sites & 198 & 300 & 71 & 84 & 39 \\
\hline $\begin{array}{l}\text { Number of public-owned water-treatment } \\
\text { plants discharging to river }\end{array}$ & 47 & 42 & 4 & 12 & 1 \\
\hline
\end{tabular}

samples collected near the peak flow during storms. Baseflow samples were collected by sampling continuously over a 6-hour period.

A unique identification number (CARP identifier) was assigned to each sample type (New Jersey Department of Environmental Protection, 2001). To simplify the tracking of samples, the various analyses of all samples collected from a single site on a particular date or during a particular storm were assigned the same USGS identifier. The USGS identifiers and the corresponding CARP identifiers are listed in table 4.

\section{Methods of Sample Collection and Analysis}

The equipment and methods used to collect streamflow and quality-assurance samples are described in this section. Methods of analysis used in the laboratory also are described.

\section{Field Methods}

This section describes the sampling equipment used in the field as well as the configuration of the equipment as it was deployed at each site along the various rivers. This section also contains information on quality-assurance samples collected in this study.

\section{Sampling-Station Equipment}

Water-quality sampling stations were constructed adjacent to previously installed USGS stream-gaging stations located near the head of tide on each river (table 1). The stream-gaging stations are actively maintained and provide real-time discharge data. The sampling apparatus are housed in a concrete bunker equipped with electrical service (fig. 3). Two polytetrafluoroethylene (PTFE) and one polypropylene tubing line, all encased in a protective plastic or steel pipe containing an electrical heating coil for cold weather use, 


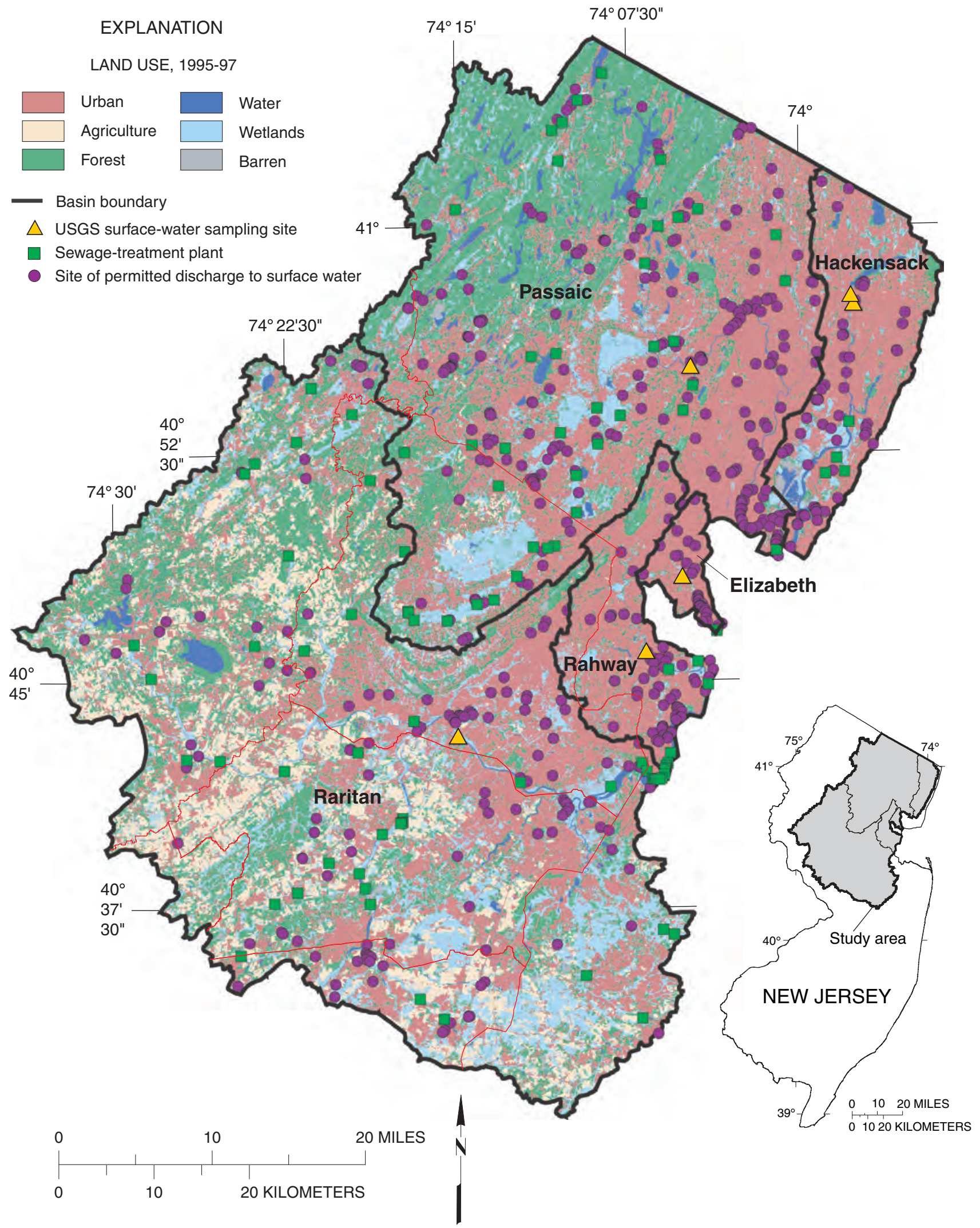

Figure 2. Land use in the five-river-basin study area, N.J. 
Table 3. Description of sample types collected from, and equipment used in, the Raritan, Passaic, Hackensack, Rahway and Elizabeth Rivers, New Jersey.

[TOPS, Trace Organic Platform Sampler; XAD, chemical exchange resin; ISCO, automatic sampler; PCB, Polychlorinated biphenyl; PAH, polycyclic aromatic hydrocarbon]

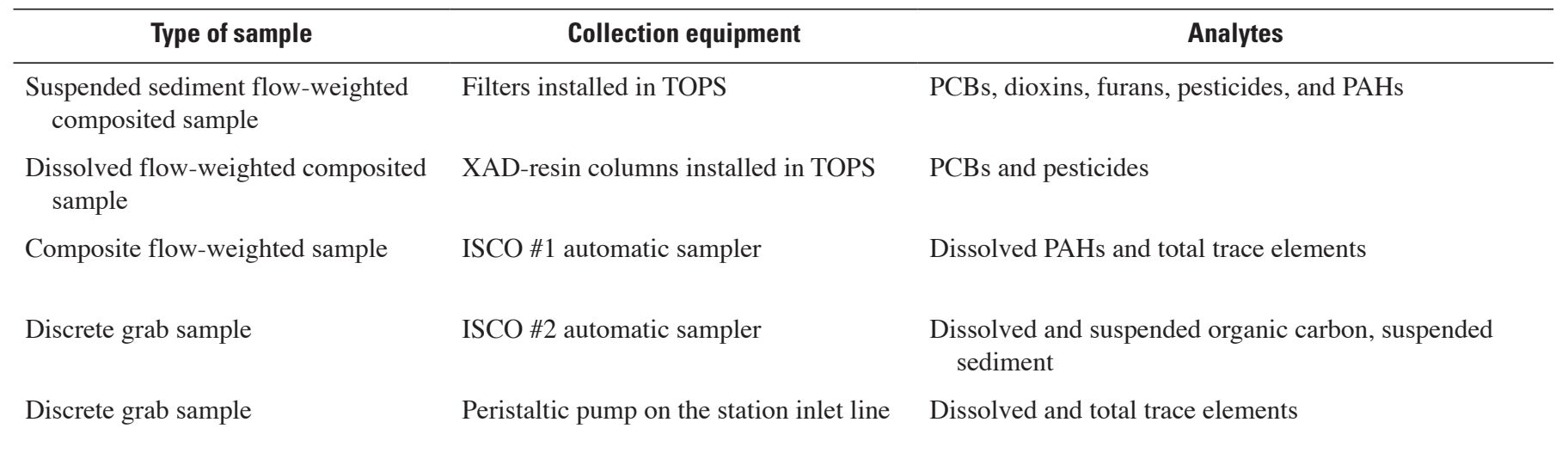

run from each station to the thalweg of the river. The tubing extends 1 to 2 feet downstream from the end of the protective casing. The tubing is buried underground between the streambank and the sampling stations. The inlet tubing for all sampling stations, except the one on the Elizabeth River, is connected to a large peristaltic pump that allows the streamwater to be continually pumped into the station during sampling. This pump is activated by the automatic sampler used to monitor river stage.

The type of sampling that was conducted was called point sampling, which means the intake was at one point in the river. The USGS preferred method of sampling is done by using equal width interval (EWI) or equal discharge interval (EDI) sampling that results in a representative sample over the cross section of the river. In order for point sampling to elicit representative samples, the river must be well-mixed. A separate study was executed to determine whether the rivers studied in this project were well-mixed and single-point sampling methods were appropriate. (Data are on file at the USGS New Jersey Water Science Center.) The end result was that all five rivers were well-mixed and single point sampling fell within the range of EWI samples in terms of conductivity, suspended sediment concentration, particulate organic carbon concentrations, and dissolved organic carbon concentrations.

\section{Sampler Configuration}

Each station contains two ISCO-6700 automatic samplers (ISCO \#1 and \#2 samplers), a Trace Organic Platform Sampler (TOPS), and telecommunication and control equipment (fig. 4). The ISCO \#1 sampler is connected to a pressure transducer, buried in the streambed, that senses the river stage. The sampler records the stage at 5-minute intervals and converts the stage reading to a discharge value. The stage reading monitored by the ISCO \#1 sampler was used to activate the other samplers. The stage-discharge relation from the adjacent USGS gaging station was used to program the ISCO \#1 sampler at all sampling stations except the one on the Elizabeth River. Because the gaging station is downstream from the sampling station, the stage-discharge relation at the Elizabeth River sampling station was measured independently.

The three samplers were configured to collect different types of samples, as described in detail in the USGS Standard Operating Procedures (SOP) in the New Jersey Toxics Reduction Workplan SOP (New Jersey Department of Environmental Protection, 2001). The ISCO \#1 sampler recorded stage, and instantaneous and cumulative discharge, and served to activate itself, the station's peristaltic pump, and the other samplers when the river stage rose above a preset level (typically 0.2 feet above the pre-storm stage). To produce flow-weighted average composite samples, the ISCO \#1 sampler tracked the cumulative river discharge and, when the preset volume had passed the station, started the other samplers to collect river water. The flow interval volumes were approximated with historical hydrographs and by trial-and-error, with the goal of collecting and compositing 40 aliquots of river water during each storm. For base-flow sampling, the TOPS was run continuously until the target volume of water had been processed (at least $50 \mathrm{~L}$ had passed through the XAD-resin columns during an approximate 6-hour period), whereas the other automatic samplers collected at least four discrete aliquots spaced equally throughout the sampling period.

The ISCO \#1 sampler collected two 100-mL aliquots during each sampling cycle that were pumped into two 4-L, class-A level clean, glass bottles. One sample was analyzed for total trace elements and the second for dissolved polycyclic aromatic hydrocarbons (PAHs). The sample analyzed for PAHs was needed because the XAD-2 resin used in the TOPS is known to produce naphthalene-based compounds over time, which would interfere with analysis for PAHs (David 
Table 4. Sample identifiers, collection dates, and sites for samples collected from the Raritan, Passaic, Hackensack, Rahway and Elizabeth Rivers, New Jersey

[USGS, U.S. Geological Survey, CARP, Contaminant Assessment Reduction Program; TOPS, Trace Organic Platform Sampler; XAD, chemical exchange resin; PAHs, Polycyclic aromatic hydrocarbons; NC, sample not collected]

\begin{tabular}{|c|c|c|c|c|c|c|c|c|}
\hline \multicolumn{4}{|c|}{ USGS Sample Information } & \multicolumn{5}{|c|}{ CARP Sample Identifiers } \\
\hline $\begin{array}{l}\text { USGS Sample } \\
\text { Identifier }\end{array}$ & $\begin{array}{c}\text { Date } \\
\text { collected }\end{array}$ & River & $\begin{array}{l}\text { Flow } \\
\text { regime }\end{array}$ & $\begin{array}{l}\text { TOPS XAD-resin } \\
\text { sample analyzed for } \\
\text { organic compounds, } \\
\text { dissolved in water }\end{array}$ & $\begin{array}{l}\text { TOPS filter sample } \\
\text { analyzed for organic } \\
\text { compounds in } \\
\text { sediment }\end{array}$ & $\begin{array}{c}\text { Composite sample } \\
\text { analyzed for PAHs, } \\
\text { dissolved }\end{array}$ & $\begin{array}{l}\text { Composite sample } \\
\text { for total trace } \\
\text { elements }\end{array}$ & $\begin{array}{l}\text { Grab sample for } \\
\text { dissolved- and } \\
\text { particulate- phase } \\
\text { trace elements }\end{array}$ \\
\hline PASS0602200 & $6 / 22 / 00$ & Passaic & Base flow & 1USG00011SA & 1USG00012SA & 1USG00013SC & $\mathrm{NC}$ & 1USG00016SA \\
\hline HACK062300 & $6 / 23 / 00$ & $\begin{array}{l}\text { Hackensack } \\
\quad \text { (freshwater) }\end{array}$ & Base flow & 1USG00001SA & 1USG00005SA & 1USG00007SC & $\mathrm{NC}$ & 1USG00009SA \\
\hline RARI062700 & $6 / 27 / 00$ & Raritan & Base flow & 1USG00017SA & 1USG00018SA & 1USG00019SC & $\mathrm{NC}$ & 1USG00021SA \\
\hline RAHW062800 & $6 / 28 / 00$ & Rahway & Base flow & 1USG00022SA & 1USG00023SA & 1USG00024SC & $\mathrm{NC}$ & 1USG00026SA \\
\hline ELIZ062900 & $6 / 29 / 00$ & Elizabeth & Base flow & 1USG00027SA & 1USG00028SA & 1USG00029SC & 1USG00030SC & 1USG00031SA \\
\hline PASS121500 & $12 / 15 / 00$ & Passaic & Variable & 1USG00032SA & 1USG00034SA & 1USG00036SC & $\mathrm{NC}$ & 1USG00037SA \\
\hline HAC4031301 & $3 / 13 / 01$ & $\begin{array}{l}\text { Hackensack } \\
\text { (tidal) }\end{array}$ & Tidal & 1USG00040SA & 1USG00043SA & 1USG00044SC & 1USG00046SC & 1USG00048SA \\
\hline PASS031401 & $3 / 14 / 01$ & Passaic & Stormflow & 1USG00051SA & 1USG00053SA & 1USG00055SC & 1USG00057SC & 1USG00059SA \\
\hline RARI041301 & $4 / 13 / 01$ & Raritan & Stormflow & 1USG00062SA & 1USG00065SA & 1USG00067SC & 1USG00069SC & 1USG00071SA \\
\hline ELIZ042501 & $4 / 25 / 01$ & Elizabeth & Base flow & 1USG00074SA & 1USG00075SA & 1USG00076SC & 1USG00078SC & 1USG00080SA \\
\hline RAHW042501 & $4 / 25 / 01$ & Rahway & Base flow & 1USG00083SA & 1USG00085SA & 1USG00087SC & 1USG00089SC & 1USG00091SA \\
\hline RAHW052201 & $5 / 22 / 01$ & Rahway & Stormflow & 1USG00093SA & 1USG00096SA & 1USG00098SC & 1USG00100SC & 1USG00102SA \\
\hline ELIZ052201 & $5 / 22 / 01$ & Elizabeth & Stormflow & 1USG00105SA & 1USG00106SA & 1USG00107SC & 1USG00109SC & 1USG00111SA \\
\hline RARI100401 & $10 / 4 / 01$ & Raritan & Base flow & 1USG00113SA & 1USG00116SA & 1USG00118SC & 1USG00119SC & 1USG00121SA \\
\hline PASS101701 & $10 / 17 / 01$ & Passaic & Base flow & 1USG00124SA & 1USG00125SA & 1USG00126SC & 1USG00128SC & 1USG00129SA \\
\hline HACK101901 & $10 / 19 / 01$ & $\begin{array}{l}\text { Hackensack } \\
\text { (freshwater) }\end{array}$ & Base flow & 1USG00131SA & 1USG00132SA & 1USG00133SC & 1USG00135SC & 1USG00136SA \\
\hline RARI030302 & $3 / 3 / 02$ & Raritan & Stormflow & 1USG00138SA & 1USG00141SA & 1USG00142SC & 1USG00144SC & 1USG00145SA \\
\hline RARI032102 & $3 / 21 / 02$ & Raritan & Stormflow & 1USG00155SA & 1USG00156SA & 1USG00157SC & 1USG00158SC & 1USG00159SA \\
\hline RAHW042802 & $4 / 28 / 02$ & Rahway & Stormflow & 1USG00162SA & 1USG00163SA & 1USG00164SC & 1USG00166SC & 1USG00167SA \\
\hline HACK071902 & $7 / 19 / 02$ & $\begin{array}{l}\text { Hackensack } \\
\text { (freshwater) }\end{array}$ & Base flow & 1USG00172SA & 1USG00173SA & 1USG00174SC & $\mathrm{NC}$ & $\mathrm{NC}$ \\
\hline ELIZ060403 & 06/04/03 & Elizabeth & Stormflow & 1USG00175SA & 1USG00177SA & 1USG00178SC & 1USG00179SC & 1USG00180SA \\
\hline
\end{tabular}




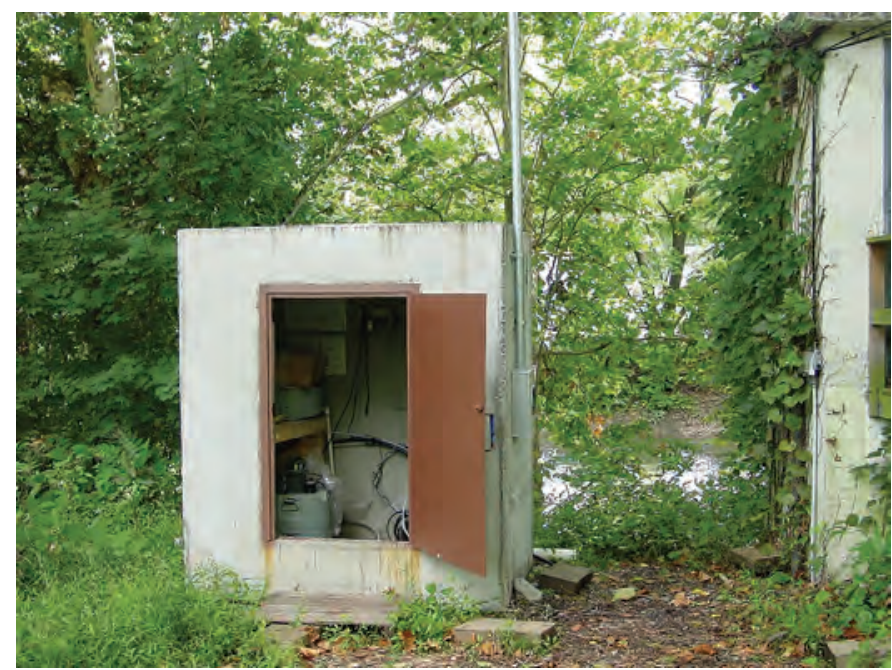

Figure 3. Water-quality sampling station on the Passaic River at Little Falls, N.J.
Thal, Severn Trent Laboratories, written commun., 1999). Every second or third cycle, an additional two aliquots (100 $\mathrm{mL}$ each) were pumped into a second set of $4-\mathrm{L}$ bottles. If the storm lasted longer than expected or if the streamflow interval was set too low, then this second set of samples was available for analysis.

After the sample aliquots were collected by the ISCO \#1 sampler, the TOPS was activated, followed by the ISCO \#2 sampler. The ISCO \#2 sampler collected two individual 1-L samples for analysis for suspended sediment (SS) and DOC and POC. The sample volumes collected by the ISCO \#1 and \#2 samplers were measured periodically during the storm to verify that an accurately composited sample was being produced.

The TOPS (figs. 5 and 6), modified from a sampler designed by the New York State Department of Environmental Conservation (1998), is used to collect large volumes of river water with suspended sediment that are required for analysis of trace amounts of dissolved and suspended constituents such as dioxins and pesticides. After the ISCO \#1 sampler collected a sample, the TOPS pumped preset volumes of river water

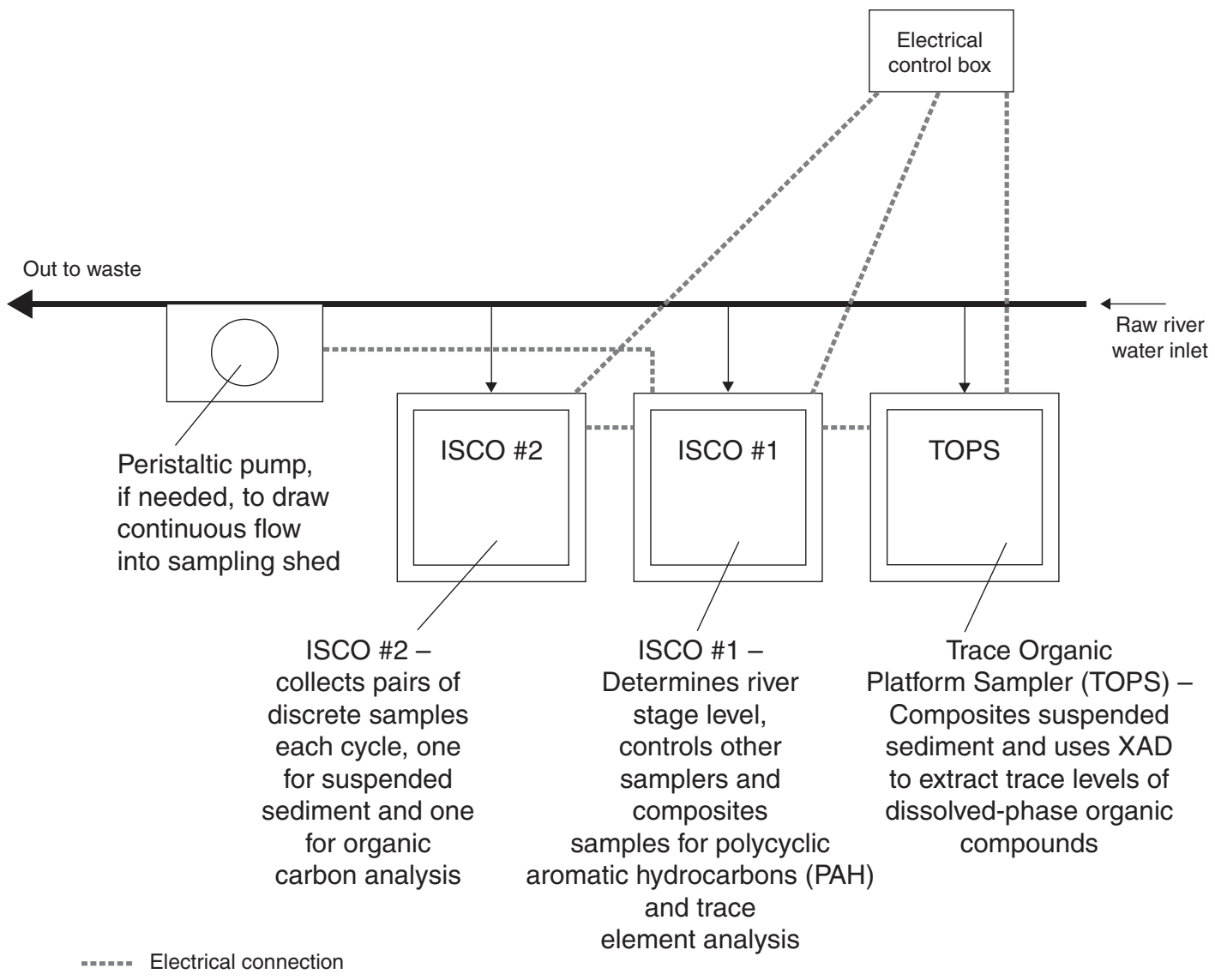

Figure 4. Schematic diagram showing the configuration of the automatic samplers. 
through filters and chemical exchange XAD-resin columns. Suspended sediment was collected on a 0.5 -micron nominal pore-size glass fiber (GFF) canister filter, $5 \mathrm{~cm}$ in diameter and $10 \mathrm{~cm}$ in length. Repeated measurements of suspended sediment concentrations in the outflow demonstrated that the canister filter efficiency was 90 percent. The filtered water then was split into two streams, one stream (90 percent) went to waste and the second stream (10 percent) passed through a 1.0-micron pore-size, $142-\mathrm{mm}$ diameter glass fiber flat filter, then through two XAD-resin columns connected in series. Each column contained approximately 125 grams of pre-cleaned XAD-2 resin held in place with a pre-cleaned PTFE screen. The columns are designed to sequester dissolved organic compounds from large volumes of water. For analysis, the XAD-2 resin from both columns was removed and combined in a Soxhlet extractor, then extracted using a hexane-acetone solvent mixture that can be analyzed using gas chromatography (GC). The XAD-2 resin was not used again for sample collection. The XAD resin used in these columns, Supelco Amberlite XAD Type 2, is a polyaromatic chemical exchange resin of hydrophobic cross-linked polystyrene copolymers, existing as 20 to 60 mesh-sized beads formulated to absorb hydrophobic compounds up to 20,000 molecular weight. The beads are an agglomeration of microspheres that produce a continuous gel phase and a continuous pore phase. The open-cell porous structure allows water to easily penetrate pores. In the adsorption process, the hydrophobic part of the adsorbate molecule is preferentially adsorbed onto the hydrophobic polystyrene surface of the XAD-2 resin, whereas the hydrophilic compounds remain in the aqueous phase. Adsorbed compounds do not penetrate the surface of the microsphere but remain on the surface of the XAD-2 resin beads where they can be eluted with organic solvents. The selectivity and extent of adsorption of soluble organic compounds by XAD-2 resin increases as the hydrophobicity of the adsorbate molecule increases. The XAD-2 resin has an approximate pore volume of $0.65 \mathrm{~mL} / \mathrm{g}$, a wet density of 1.02 gram per milliliter, a mean surface area of 300 square meters per gram, a mean pore diameter of 90 Angstroms, and a mesh size of 20 to 60. (New York Department of Environmental Conservation, 1998)

The columns were prepared at a certified laboratory by back-washing the XAD-2 resin into each column, then spiking the inflow end of selected columns with carbon- $13\left({ }^{13} \mathrm{C}\right)$ and deuterated labeled internal standards that represent each class of compound studied (table 5). Labeled field surrogates are used to give an indication of the trapping and recovery efficiency of the columns and analytical methods, and results are reported for the dissolved phase, in units of percent recovered.

Two pumps drive water through the TOPS, a peristaltic pump that pulls water from the inlet line and pushes it through the canister filter and a piston pump that pulls water from the canister outfall through the XAD-resin columns (fig. 6). The volume of effluent water controls the operating time of the respective pumps. Typically during each cycle of the sampler, $9.5 \mathrm{~L}$ of water was pumped through the canister filter at a rate

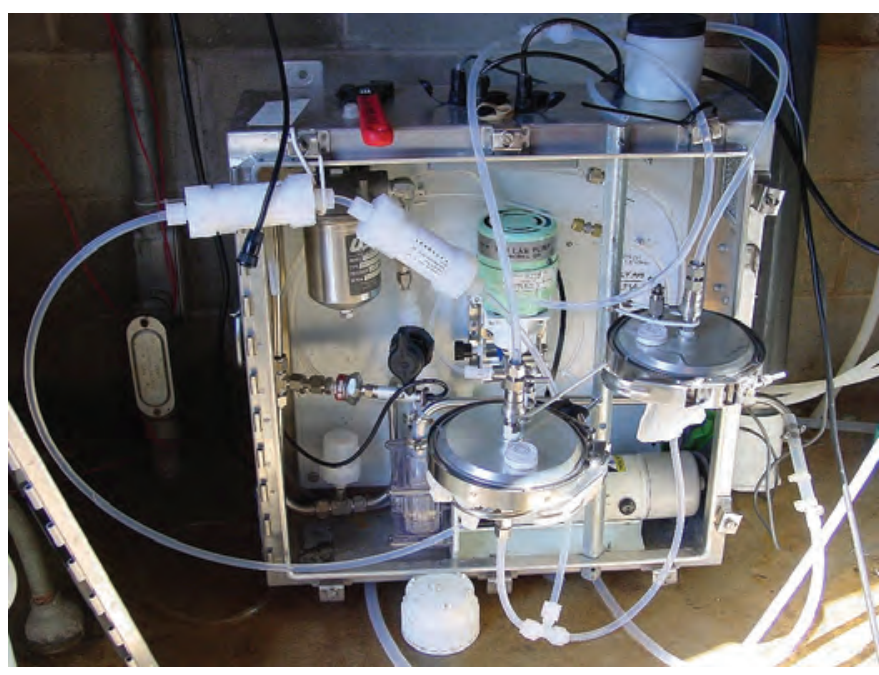

Figure 5. A Trace Organic Platform Sampler (TOPS) used to collect water samples.

of approximately $1.5 \mathrm{~L} / \mathrm{min}$ and collected in a control reservoir; $1.5 \mathrm{~L}$ of this filtered water was pumped through the flat filter and XAD-resin columns at a rate of approximately 100 to $150 \mathrm{~mL} / \mathrm{min}$ and collected in a second control reservoir. After the required volume was collected in the two reservoirs, the pumps were shut off and solenoid valves were opened to allow the reservoirs to drain into large collection carboys. The volume of the processed water was carefully measured at the conclusion of the sampling event to determine the total volume that passed through the filters and columns. Target volumes of $500 \mathrm{~L}$ of water for passage through the canister filter and $50 \mathrm{~L}$ for passage through the XAD-resin columns, along with the analytical methods, were used to set the minimum level of mass of the constituents that could be observed. In practice, the total volume collected was dependent upon the ultimate length of the storm and the choice of the preset streamflow interval volume. The final total volume processed through the XAD-resin columns was used to calculate concentrations of dissolved constituents. The mass of suspended sediment trapped on the filters was calculated using the total volume of water processed and the corresponding geometric mean of the suspended sediment concentrations in the discrete grab samples collected in the ISCO \#2 sampler. Most of the samples collected in the TOPS required the use of one canister filter and multiple flat filters. All filters were combined for analysis.

In addition to the composite samples collected in the ISCO \#1 sampler for analysis for total trace elements and PAHs, individual grab samples were collected for analysis for total and dissolved trace elements. Typically, these samples were collected near the peak of the river stage during a storm. Samples were collected by connecting a short piece of pre-cleaned PTFE tubing to the inlet line and using a small peristaltic pump to draw a sample into a pre-cleaned PTFE 


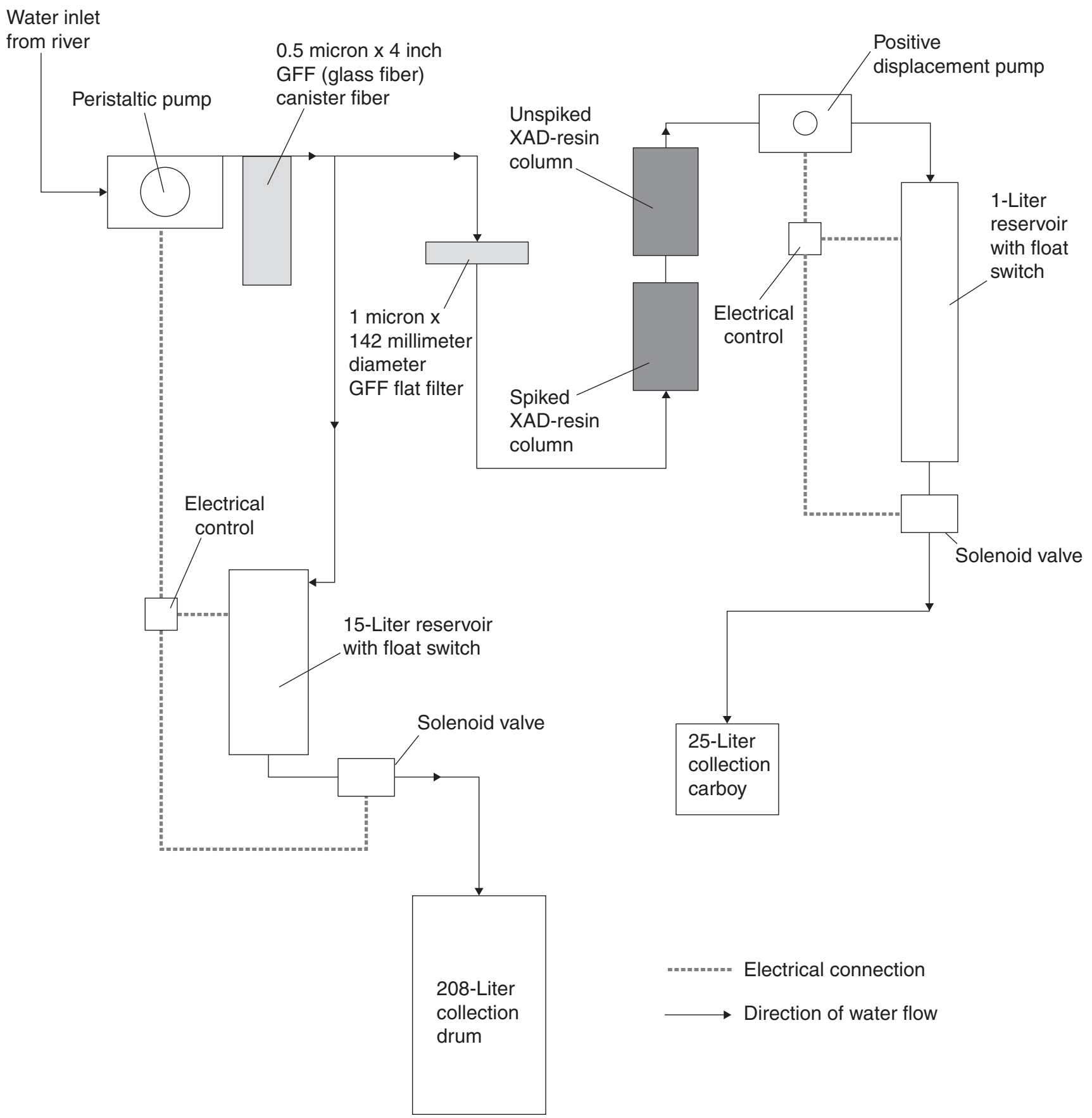

Figure 6. Schematic diagram of a Trace Organic Platform Sampler (TOPS). 
Table 5. Carbon-13 and chlorine-37 labeled field surrogates used with the XAD-resin columns

[BZ\#, Ballschmiter and Zell number; L, liter; TCDD, Tetrachlorodibenzo-pdioxin; BHC, Benzenehexachloride]

\begin{tabular}{llc}
\hline $\begin{array}{c}\text { Compound } \\
\text { class }\end{array}$ & $\begin{array}{c}\text { Labeled standard } \\
\text { compound (BZ\#) }\end{array}$ & $\begin{array}{c}\text { Mass of spiking solution } \\
\text { added to first column } \\
\text { (nanograms) }\end{array}$ \\
\hline $\begin{array}{c}\text { Polychlorinated } \\
\text { Biphenyls }\end{array}$ & ${ }^{13} \mathrm{C}_{12}-31 \mathrm{~L}$ & 80 \\
$\begin{array}{c}\text { Polychlorinated } \\
\text { Biphenyls }\end{array}$ & ${ }^{13} \mathrm{C}_{12}-95 \mathrm{~L}$ & 80 \\
$\begin{array}{c}\text { Polychlorinated } \\
\text { Biphenyls }\end{array}$ & ${ }^{13} \mathrm{C}_{12}-153 \mathrm{~L}$ & 80 \\
Dioxins & ${ }^{37} \mathrm{Cl}-2,3,7,8-\mathrm{TCDD}$ & .8 \\
Pesticides & ${ }^{13} \mathrm{C}_{6}$-Alpha-BHC & 80 \\
\hline
\end{tabular}

bottle. Filtered samples were collected by attaching a precleaned 0.45-micron capsule filter to the tubing and slowly (approximately $100 \mathrm{~mL} / \mathrm{min}$ ) pumping water directly into a PTFE bottle. Unfiltered samples were collected for analysis of total trace elements (cadmium $(\mathrm{Cd})$, lead $(\mathrm{Pb})$, mercury $(\mathrm{Hg})$, and methyl-mercury $(\mathrm{MeHg})$ ), whereas filtered samples were collected for analysis for dissolved trace elements. The pump tubing, filters, bottles, and PTFE tubing that were used were provided acid-cleaned by the contract laboratory. Each grab sample consisted of one 500-mL sample of unfiltered water for analysis for total trace elements, one unfiltered 500-mL sample for total methyl-mercury, one filtered 500-mL sample for dissolved trace elements, and one filtered 500-mL sample for dissolved MeHg.

\section{Quality-Assurance Samples}

Many field and equipment blanks were collected during the sampling to demonstrate the integrity and quality of the samples collected from the rivers (table 6). The field blanks are used to determine whether contaminants are present in the XAD-2 resin and filtering media prior to sampling, and to demonstrate whether contaminants are derived from the sampling environment. Equipment blanks were used to demonstrate the cleanliness of the TOPS, the tubing, and the filters provided for analysis for trace elements, and to determine whether cross contamination occurred between the composite samples collected with the ISCO \#1 sampler. Because of the high cost of analysis, all of the field and equipment blanks collected were not analyzed for each sampling site for each storm or base-flow event. Equipment blanks, for example, were made by cleaning all of the TOPS together, and randomly selecting one for use in collecting an equipment blank that served for the next TOPS deployments ( 3 or 4 storms or baseflow events). Field blanks were collected on a schedule of one blank for one to three storm or base-flow events. The various blanks and their associated samples are identified in the field data in table 7 (on CD at end of report).

\section{Sample Handling}

At the conclusion of a storm or a base-flow event, the samples were labeled and returned to the USGS New Jersey Water Science Center (WSC) laboratory for processing and shipping to the various certified contract laboratories. The sample handling and chain-of-custody requirements were developed by the NJDEP for CARP. The filters and XAD-resin columns were wrapped in new, clean aluminum foil and sealed in polyethylene bags, and together with sample bottles were kept on ice or refrigerated. Samples were shipped in coolers, typically within 48 hours of collection.

Samples for analysis for SS collected with the ISCO \#2 sampler were sent directly to the USGS Kentucky WSC Sediment Laboratory. Samples to be analyzed for POC (also collected with the ISCO \#2 sampler) were processed in the New Jersey WSC laboratory by filtering a known volume of water through three 25-mm pre-baked glass fiber filters. The filters were wrapped in pre-baked foil, double bagged, and frozen before shipping. At least $60 \mathrm{~mL}$ of filtered water to be analyzed for DOC was collected in pre-baked, amber glass bottles, acidified with $1 \mathrm{~mL}$ of ultrapure concentrated $(4.5 \mathrm{~N})$ sulfuric acid and sent to the National Water Quality Laboratory in Denver, Colorado. Samples for analysis of total trace elements and dissolved PAHs were prepared by vigorously shaking, then pouring water directly from the 4-L glass collection bottles into pre-cleaned PTFE and glass bottles, respectively. At least $2 \mathrm{~L}$ of water was submitted for analysis of PAHs, and $500 \mathrm{~mL}$ was submitted for analysis of trace elements.

\section{Laboratory Methods}

Four laboratories were used in this project, each for a different type of analysis (table 8). Concentrations of SS were measured by filtration and gravimetric analysis at the USGS Kentucky WSC Sediment Laboratory in Louisville, Kentucky (Sholar and Shreve, 1998). Concentrations of DOC and POC were measured at the USGS National Water Quality Laboratory in Denver, Colorado, using infrared (IR) spectroscopy methods (Zimmermann and others, 1997; Burkhardt and others, 1997). Concentrations of total and dissolved trace elements were measured by a contract laboratory, Frontier Geosciences. Concentrations of $\mathrm{Cd}$ and $\mathrm{Pb}$ were measured using inductively coupled plasma-mass spectrometry (ICP$\mathrm{MS})$. Concentrations of $\mathrm{Hg}$ were measured using cold-vapor atomic fluorescence spectrometry (CV-AFS), and concentra- 
Table 6. Description of blank samples used for quality assurance

[XAD, chemical exchange resin; PCBs, Polychlorinated biphenyls; PAHs, Polycyclic aromatic hydrocarbons; L, liter; mL, milliliter]

\begin{tabular}{|c|c|c|}
\hline Type of Blank & Analytes & Summary of method \\
\hline XAD-resin equipment blank & Dissolved pesticides and PCBs & $\begin{array}{l}\text { After cleaning, } 50 \mathrm{~L} \text { of organic-free, de-ionized water is pumped through a } \\
\text { spiked XAD-resin column in the laboratory. }\end{array}$ \\
\hline XAD-resin field blank & Dissolved pesticides and PCBs & $\begin{array}{l}\text { When XAD-resin columns are installed in the field, a second set of two } \\
\text { columns is opened and exposed to the same conditions as the sampling } \\
\text { columns. }\end{array}$ \\
\hline Auto-sampler field blank & Total trace elements or PAHs & $\begin{array}{l}\text { One } 500-\mathrm{mL} \text { bottle filled with organic-free de-ionized laboratory water is } \\
\text { opened and placed in the center of the automatic sampler's rosette. The } \\
\text { bottle is left uncapped during the time the sample is being collected. }\end{array}$ \\
\hline Grab equipment blank & Dissolved methyl-mercury & $\begin{array}{l}\text { Before collection of a grab sample for analysis for dissolved trace ele- } \\
\text { ments, } 500 \text {-mL of organic-free, de-ionized laboratory water is pumped } \\
\text { through the pre-cleaned tubing and filtered in the field. }\end{array}$ \\
\hline Grab field blank & Total trace elements & $\begin{array}{l}\text { When a grab sample is collected for analysis for total trace elements, one } \\
500 \text {-mL bottle of organic-free, de-ionized laboratory water is opened and } \\
\text { exposed to the same field conditions as the samples. }\end{array}$ \\
\hline Grab field blank & Total methyl-mercury & $\begin{array}{l}\text { When a grab sample is collected for analysis for total trace elements, one } \\
500 \text {-mL bottle of organic-free, de-ionized laboratory water is opened and } \\
\text { exposed to the same field conditions as the sample. }\end{array}$ \\
\hline
\end{tabular}

tions of $\mathrm{MeHg}$ were measured using aqueous phase ethylation, isothermal GC separation, and CV-AFS detection. Concentrations of organic compounds in the dissolved and particulate phases were determined by Severn Trent Laboratories.

Analysis for organic compounds included measurement of the individual congeners of PCBs, and a suite of dioxins, furans, PAHs, and pesticides (table 8). The analytical methods used in this study for trace organic compounds (table 9) were modified from NYSDEC and U.S. Environmental Protection Agency (USEPA) methods and involve the use of the isotope dilution/internal standard methods. The isotope dilution method uses various ${ }^{13} \mathrm{C}$ and deuterated labeled internal standards that are added to each sample before extraction, before cleanup of the extract, and before injection. High-resolution gas chromatography and mass spectrometry (HR GC/MS) was used for the analysis for PCBs, dioxins, and pesticides, and low resolution GC/MS was used for analysis for PAHs. For the individual dioxins and PAHs, and for the PCB homolog groups, directly analogous labeled standards were available. For some pesticides, however, directly analogous labeled compounds (analogs) were not available, so closely related labeled compounds were used instead. As a result, the pesti- cide method is more properly termed a "standard addition" analysis. These methods are predicated on the assumption that the labeled standards and the native compounds behave identically in the preparation and analysis steps. This has been demonstrated for dioxins, PCBs, and PAH compounds. The lack of direct labeled analogs for pesticide analysis (for example, compound-fragmentation in the GC column) added to the uncertainty of some of the pesticide results. Recoveries of the internal standards for all analytes generally were within the range of 20 to 150 percent, which is considered an acceptable range for internal standard recovery. Exceptions include some of the pesticides and a few PCBs. For recoveries for PCBs and dioxins as low as 10 percent, the analytic results probably can be considered accurate (Dave Thal, Severn Trent Laboratories, oral commun., 2001).

Mass spectrometry methods provide unambiguous identification of compounds along with high sensitivity for the compounds sought in the samples; however, some of the PCB congeners do not separate on the column selected by the CARP (Supelco Phase-Bonded-Octyl column, 60-meters long) and co-elute as mixtures of isomers. Individual congeners in co-elutions cannot be distinguished on the basis of mass 
Table 8. Constituents in sediment and water samples collected from the Raritan, Passaic, Hackensack, Rahway, and Elizabeth Rivers, New Jersey

[CAS, Chemical Abstract Service; IUPAC, International Union of Physical and Analytical Chemistry; PCB, Polychlorinated biphenyl; n/a, not applicable]

\begin{tabular}{|c|c|}
\hline & CAS number \\
\hline \multicolumn{2}{|c|}{ Monochlorobiphenyls } \\
\hline 3 & 2051-62-9 \\
\hline \multicolumn{2}{|c|}{ Dichlorobiphenyls } \\
\hline 4 & $13029-08-8$ \\
\hline 5 & $16605-91-7$ \\
\hline 8 & $34883-43-7$ \\
\hline 10 & $33146-45-1$ \\
\hline 11 & $2050-67-1$ \\
\hline 15 & $2050-68-2$ \\
\hline \multicolumn{2}{|c|}{ Trichlorobiphenyls } \\
\hline 16 & $38444-78-9$ \\
\hline 17 & $37680-66-3$ \\
\hline 18 & $37680-65-2$ \\
\hline 19 & $38444-73-4$ \\
\hline 20 & $38444-84-7$ \\
\hline 22 & $38444-85-8$ \\
\hline 25 & $55712-37-3$ \\
\hline 26 & $38444-81-4$ \\
\hline 27 & $38444-76-7$ \\
\hline 28 & $7012-37-5$ \\
\hline 31 & $16606-02-3$ \\
\hline 33 & $38444-86-9$ \\
\hline 37 & $38444-90-5$ \\
\hline \multicolumn{2}{|c|}{ Tetrachlorobiphenyls } \\
\hline 40 & $38444-93-8$ \\
\hline 42 & $36559-22-5$ \\
\hline 43 & $70362-46-8$ \\
\hline 44 & $41464-39-5$ \\
\hline 45 & $70362-45-7$ \\
\hline 46 & $41464-47-5$ \\
\hline 47 & $2437-79-8$ \\
\hline
\end{tabular}

\begin{tabular}{|c|c|}
\hline Name or IUPAC PCB number & CAS number \\
\hline 48 & $70362-47-9$ \\
\hline 49 & $41464-40-8$ \\
\hline 50 & $62796-65-0$ \\
\hline 52 & $35693-99-3$ \\
\hline 53 & 41464-41-9 \\
\hline 56 & 41464-43-1 \\
\hline 59 & $74472-33-6$ \\
\hline 60 & $33025-41-1$ \\
\hline 62 & $54230-22-7$ \\
\hline 63 & 74472-34-7 \\
\hline 64 & $52663-58-8$ \\
\hline 66 & $32598-10-0$ \\
\hline 70 & $32598-11-1$ \\
\hline 74 & $32690-93-0$ \\
\hline 75 & $32598-12-2$ \\
\hline 77 & $32598-13-3$ \\
\hline 81 & $70362-50-4$ \\
\hline \multicolumn{2}{|c|}{ Pentachlorobiphenyls } \\
\hline 82 & $52663-62-4$ \\
\hline 83 & $60145-20-2$ \\
\hline 84 & $52663-60-2$ \\
\hline 85 & $65510-45-4$ \\
\hline 86 & $55312-69-1$ \\
\hline 87 & $38380-02-8$ \\
\hline 90 & $68194-07-0$ \\
\hline 91 & 68194-05-8 \\
\hline 92 & $52663-61-3$ \\
\hline 95 & $38379-99-6$ \\
\hline 97 & $41464-51-1$ \\
\hline 99 & $38380-01-7$ \\
\hline 101 & $37680-73-2$ \\
\hline
\end{tabular}

\begin{tabular}{ll}
\hline Name or IUPAC PCB number & CAS number \\
\hline 104 & $56558-16-8$ \\
105 & $32598-14-4$ \\
109 & $74472-35-8$ \\
110 & $38380-03-9$ \\
114 & $74472-37-0$ \\
118 & $31508-00-6$ \\
119 & $56558-17-9$ \\
123 & $65510-44-3$ \\
126 & $57465-28-8$ \\
\hline & Hexachlorobiphenyls \\
\hline 128 & $38380-07-3$ \\
132 & $38380-05-1$ \\
134 & $52704-70-8$ \\
135 & $52744-13-5$ \\
136 & $38411-22-2$ \\
137 & $35694-06-5$ \\
138 & $35065-28-2$ \\
141 & $52712-04-6$ \\
146 & $51908-16-8$ \\
147 & $68194-13-8$ \\
149 & $38380-04-0$ \\
151 & $52663-63-5$ \\
153 & $35065-27-1$ \\
154 & $60145-22-4$ \\
156 & $38380-08-4$ \\
157 & $69782-90-7$ \\
158 & $74472-42-7$ \\
166 & $41411-63-6$ \\
167 & $52663-72-6$ \\
168 & $59291-65-5$ \\
169 & $32774-16-6$ \\
\hline
\end{tabular}

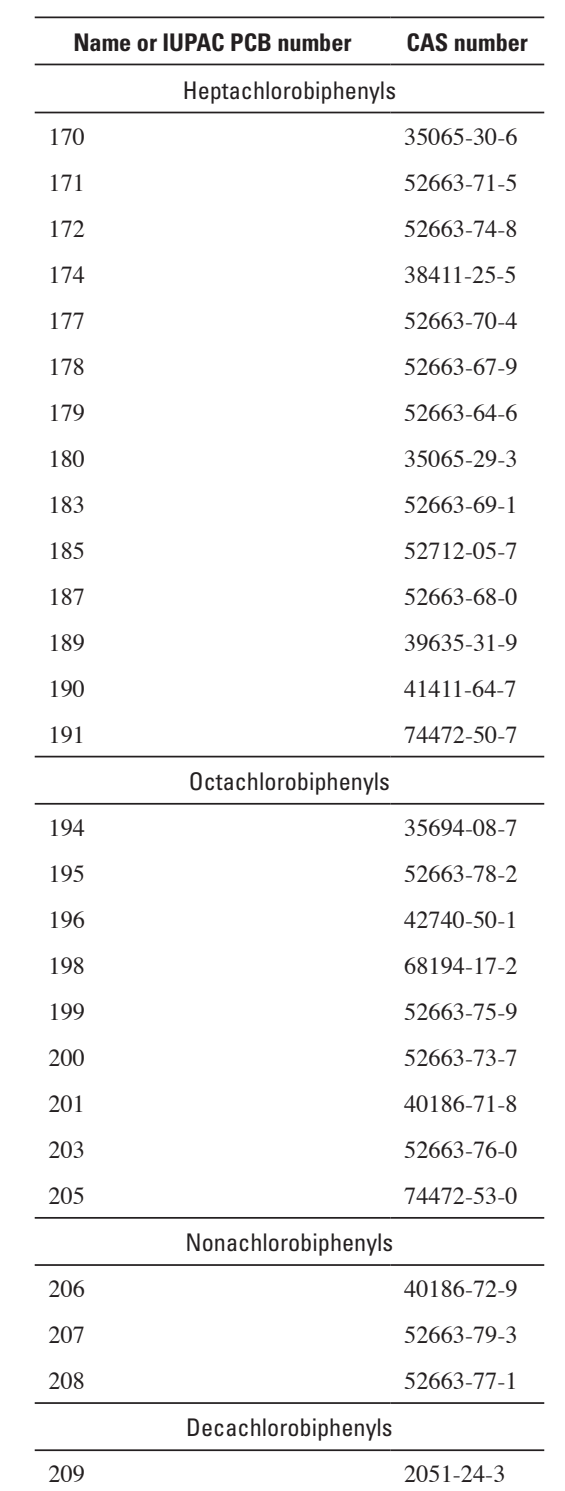


Table 8. Constituents in sediment and water samples collected from the Raritan, Passaic, Hackensack, Rahway, and Elizabeth Rivers, New Jersey-Continued.

[CAS, Chemical Abstract Service; IUPAC, International Union of Physical and Analytical Chemistry; PCB, Polychlorinated biphenyl; n/a, not applicable]

\begin{tabular}{|c|c|c|c|}
\hline Name or IUPAC PCB number & CAS number & Name or IUPAC PCB number & CAS number \\
\hline \multicolumn{2}{|l|}{ Dioxins } & Benzo(a)anthracene & $56-55-3$ \\
\hline 2,3,7,8-Trichlorodioxin & $1746-01-6$ & Benzo(a)pyrene & $50-32-8$ \\
\hline 1,2,3,7,8-Pentachlorodioxin & 40321-76-4 & Benzo(b)fluoranthene & 205-99-2 \\
\hline 1,2,3,7,8,9-Hexachlorodioxin & 19408-74-3 & Benzo(e)pyrene & $192-97-2$ \\
\hline 1,2,3,4,7,8-Hexachlorodioxin & $39227-28-6$ & Benzo(ghi)perylene & $191-24-2$ \\
\hline $1,2,3,6,7,8$-Hexachlorodioxin & $57653-85-7$ & Benzo(k)fluoranthene & $207-08-9$ \\
\hline $1,2,3,4,6,7,8$-Heptachlorodioxin & $35822-46-9$ & Biphenyl & $92-52-4$ \\
\hline Octachlorodioxin & $3268-87-9$ & Chrysene & 218-01-9 \\
\hline Furans & & Dibenz(a,h)anthracene & $53-70-3$ \\
\hline 2,3,7,8-Trichlorodifuran & $51207-31-9$ & Fluoranthene & 206-44-0 \\
\hline 1,2,3,7,8-Pentachlorodifuran & $57117-41-6$ & Fluorene & $86-73-7$ \\
\hline 2,3,4,7,8-Pentachlorodifuran & 57117-31-4 & Indeno(1,2,3-cd)pyrene & $193-39-5$ \\
\hline $1,2,3,4,7,8$-Hexachlorodifuran & 70648-26-9 & Naphthalene & $91-20-3$ \\
\hline 2,3,4,6,7,8-Hexachlorodifuran & 60851-34-5 & C2 Alkylnaphthalenes & $\mathrm{n} / \mathrm{a}$ \\
\hline 1,2,3,7,8,9-Hexachlorodifuran & 72918-21-9 & C3 Alkylnaphthalenes & $\mathrm{n} / \mathrm{a}$ \\
\hline 1,2,3,6,7,8-Hexachlorodifuran & 57117-44-9 & \multicolumn{2}{|l|}{ Pesticides } \\
\hline 1,2,3,4,7,8,9-Heptachlorodifuran & 55673-89-7 & 2,4'-DDD & $53-19-0$ \\
\hline $1,2,3,4,6,7,8$-Heptachlorodifuran & 67562-39-4 & 2,4'-DDE & $3424-82-6$ \\
\hline Octachlorodifuran & $39001-02-0$ & 2,4'-DDT & $789-02-6$ \\
\hline \multicolumn{2}{|c|}{ Polycyclic Aromatic Hydrocarbons } & 4,4'-DDD & $72-54-8$ \\
\hline Perylene & $198-55-0$ & 4,4'-DDE & $72-55-9$ \\
\hline Phenanthrene & $85-01-8$ & 4,4'-DDT & $50-29-3$ \\
\hline Pyrene & $129-00-0$ & Aldrin & $309-00-2$ \\
\hline 1-Methylnaphthalene & $90-12-0$ & alpha-BHC & $319-84-6$ \\
\hline 1-Methylphenanthrene & $832-69-9$ & beta-BHC & $319-85-7$ \\
\hline 2,3,5-Trimethylnaphthalene & $2245-38-7$ & gamma-BHC (Lindane) & $58-89-9$ \\
\hline 2,6-Dimethylnaphthalene & $581-42-0$ & alpha-Chlordane & $5103-71-9$ \\
\hline 2-Methylnaphthalene & $91-57-6$ & gamma-Chlordane & $5103-74-2$ \\
\hline Acenaphthene & $83-32-9$ & oxy-Chlordane & $27304-13-8$ \\
\hline Acenaphthylene & $208-96-8$ & alpha-Endosulfan & $959-98-8$ \\
\hline Anthracene & $120-12-7$ & beta-Endosulfan & $33213-65-9$ \\
\hline
\end{tabular}

\begin{tabular}{ll}
\hline \multicolumn{1}{c}{ Name or IUPAC PCB number } & CAS number \\
\hline cis-Nonachlor & $5103-73-1$ \\
trans-Nonachlor & $39765-80-5$ \\
Dieldrin & $60-57-1$ \\
Endosulfan sulfate & $1031-07-8$ \\
Endrin & $72-20-8$ \\
Endrin aldehyde & $7421-93-4$ \\
Endrin ketone & $53494-70-5$ \\
Heptachlor & $76-44-8$ \\
Heptachlor epoxide & $1024-57-3$ \\
Hexachlorobenzene & $118-74-1$ \\
Methoxychlor & $72-43-5$ \\
Mirex & $2385-85-5$ \\
\hline \multicolumn{1}{c}{ Trace Elements } \\
\hline Cadmium \\
Lead \\
Mercury \\
\hline \multicolumn{2}{c}{ Other } \\
\hline Methyl-mercury & $7440-43-9$ \\
Carbon, organic & n/a \\
Suspended sediment & $\mathrm{n} / \mathrm{a}$ \\
\hline & $\mathrm{n} / \mathrm{a}$ \\
\hline
\end{tabular}


Table 9. Methods used for analysis of water and sediment samples.

[PCB, Polychlorinated biphenyl; PAHs, Polycyclic aromatic hydrocarbons; HR GC/MS, High resolution gas chromatography/mass spectrometry; ICP-MS, Inductively coupled plasma- mass spectrometry; CV-AFS, Cold vapor- atomic fluorescence spectrometry; IR, Infrared; USEPA, U.S. Environmental Protection Agency; CEPA-ARB, California Environmental Protection Agency Air Resources Board; SOP, Standard operating procedures; FGS, Frontier Geosciences]

\begin{tabular}{|c|c|c|}
\hline Analyte & Method & Reference \\
\hline PCBs & HR GC/MS & Modified USEPA Method 1668A (U.S. Environmental Protection Agency, 1999) \\
\hline Dioxin/furans & HR GC/MS & USEPA Method 1613B (U.S. Environmental Protection Agency, 1994) \\
\hline Pesticides & $\mathrm{HR}$ GC/MS & $\begin{array}{l}\text { STL KNOX ID-0014, modified from USEPA Methods } 1613 \text { and 1668A, and SW-846 } \\
\text { Method 8081(U.S. Environmental Protection Agency, 1994, 1999b, and 1998a) }\end{array}$ \\
\hline Cadmium and lead & ICP-MS & Modified USEPA Method 1638 (U.S. Environmental Protection Agency, 1996b) \\
\hline $\begin{array}{l}\text { Dissolved organic } \\
\text { carbon }\end{array}$ & IR-spectrometry & $\begin{array}{l}\text { USEPA Method } 440.0 \text { (U.S. Environmental Protection Agency, 1997) and USGS } \\
\text { Open-File Report 97-380 (Burkhardt and others, 1997) }\end{array}$ \\
\hline $\begin{array}{l}\text { Particulate organic } \\
\text { carbon }\end{array}$ & IR-spectrometry & $\begin{array}{l}\text { USEPA Method } 440.0 \text { (U.S. Environmental Protection Agency, 1997) and USGS } \\
\text { Open-File Report 97-380 (Burkhardt and others, 1997) }\end{array}$ \\
\hline Suspended Sediment & $\begin{array}{l}\text { Filtration and gravimetric } \\
\text { analysis }\end{array}$ & USGS Open-File Report 98-384 (Sholar and Shreve, 1998) \\
\hline
\end{tabular}

characteristics, thus the unique congeners cannot be positively identified. Of the 209 individual PCB congeners, 39 congeners co-elute on the Supelco Phase-Bonded-Octyl column. This study identified 114 congeners of which 16 congeners coelute. As discussed, in the section "Co-elutions of Polychlorinated Biphenyls," the co-eluting congeners are identified in the data sets.

\section{Organic Compounds, Trace Elements, Suspended Sediment, and Field and Other Selected Characteristics}

\section{Organic Compounds and Trace Elements}

Data on organic compounds and trace elements are listed in tables 10 to 17 (on CD at end of report) by analyte group. Dissolved and particulate phases of PCBs, dioxins, pesticides, and PAHs are reported as mass recovered from the XAD-resin columns and the TOPS GFF canister and flat filters. Values for composited dissolved PAHs, total trace elements, and trace elements in grab samples are reported as concentrations (mass per liter of water). A detection limit and a qualifying flag are reported, if necessary, for each constituent.

\section{Qualifiers and Detection Limits}

Results of analyses received from the contract laboratories include data qualifiers or "flags" that indicate the presence of contamination in laboratory blanks; the relation between the result and the standardization or quantification curve used; the possible presence of interfering compounds, as indicated by suppression of the chromatographic curve; and an indication that the concentration was calculated using a dilution of an initial extraction volume when necessary (table 18). The laboratory that conducted the analyses for organic compounds reported an estimation of the lower and upper quantifications limits, termed "minimum levels" (ML) and "upper calibration levels" (UCL), respectively. ML and UCL are described in detail in the references for analytical methods listed in table 9. The ML is defined as the lowest level at which the 
analytical instrument provides a reliable signal and an acceptable calibration point. In this work, the ML is the concentration or mass of analyte at the lowest calibration level used in the initial calibration after corrections for method-specific sample weights, dilution and concentration volumes, and other modifications in the procedures were made. The ML provides a reasonable estimate of the lowest concentration that can be assumed to be accurate. Organic compounds that are present at less than the ML but greater than the estimated detection limit (EDL, described below) are considered to be estimates and are flagged with a "J." For most of the organic compounds analyzed for this study, the response of the analytical methods was sufficient to allow a mass to be reported even though the value was less than the ML. The reported masses for analytes that are $\mathbf{J}$ flagged have a larger analytical error associated with them than those that are not J flagged, but the J flagged masses are still sufficiently accurate to allow their use in determining concentrations. The results for dissolved PAHs in samples collected in June 2000 were censored at the lower reporting limit of $25 \mathrm{ng} / \mathrm{L}$ (nanograms per liter). Samples collected after June 2000 were not subjected to this censoring.

The Upper Calibration Level (UCL) is defined as the concentration equivalent to the highest calibration standard used, assuming all method-specific weights, volumes, and clean up procedures are used. Results for samples containing analytes that exceed the UCL were flagged with an "E." These samples were diluted and reanalyzed, and the reported diluted concentrations were flagged with a "D." This occurred for analysis of PAH compounds in sediment.

The GC/MS analytical methods used in this study generate an estimated detection limit (EDL) for each analyte that is specific to each sample. An EDL for an organic compound not present in a sample is calculated as 2.5 times the sum of the peak-to-peak noise of the quantitation ion signal in the region of the ion chromatogram where the compound of interest would elute. The EDL for organic compounds present in a sample are calculated using the noise immediately surrounding the peak of interest. For PCBs that are present in a sample, the EDL is the sum of all noise in the elution time window for the corresponding homolog group. In this manner each compound listed in tables 10 to 17 has an EDL reported in units equivalent to the result (mass or concentration depending on the organic analyte and type of sample). Ideally, the EDLs are normalized in the same manner as the reported mass recovered. For example, when calculating the dissolved concentration, the mass of compound recovered in the XAD-resin column extraction is divided by the volume of water processed through the XAD-resin columns. If no compound is recovered ( $\mathrm{U}$ flag), the detection limit is defined as the EDL divided by the volume of water that passed through the XAD-resin columns. A similar manipulation of the EDL is made for constituent concentrations associated with the SS, which is calculated using the mass of SS captured by and on the filters.

Results of analyses for trace elements, POC, and DOC include the estimated Method Detection Limits (eMDLs), which are calculated from studies performed by the contract laboratory. These eMDLs change only if a dilution or concentration of a sample was required for the analysis. Minimum levels for mercury, as defined in EPA Method 1631B, are the lowest level at which the entire analytical system will give a recognizable signal and acceptable calibration point for the analyte (U.S. Environmental Protection Agency, 1999a). As with the analyses for organic compounds, the eMDL for trace elements is generally the lowest calibration point. The eMDL was set at 3.18 times the MDL. The eMDLS and MDLs for each constituent are listed adjacent to the masses reported by the laboratory. Typical ranges for these eMDLs and MDLs

Table 18. Description of data qualifiers included in analytical results.

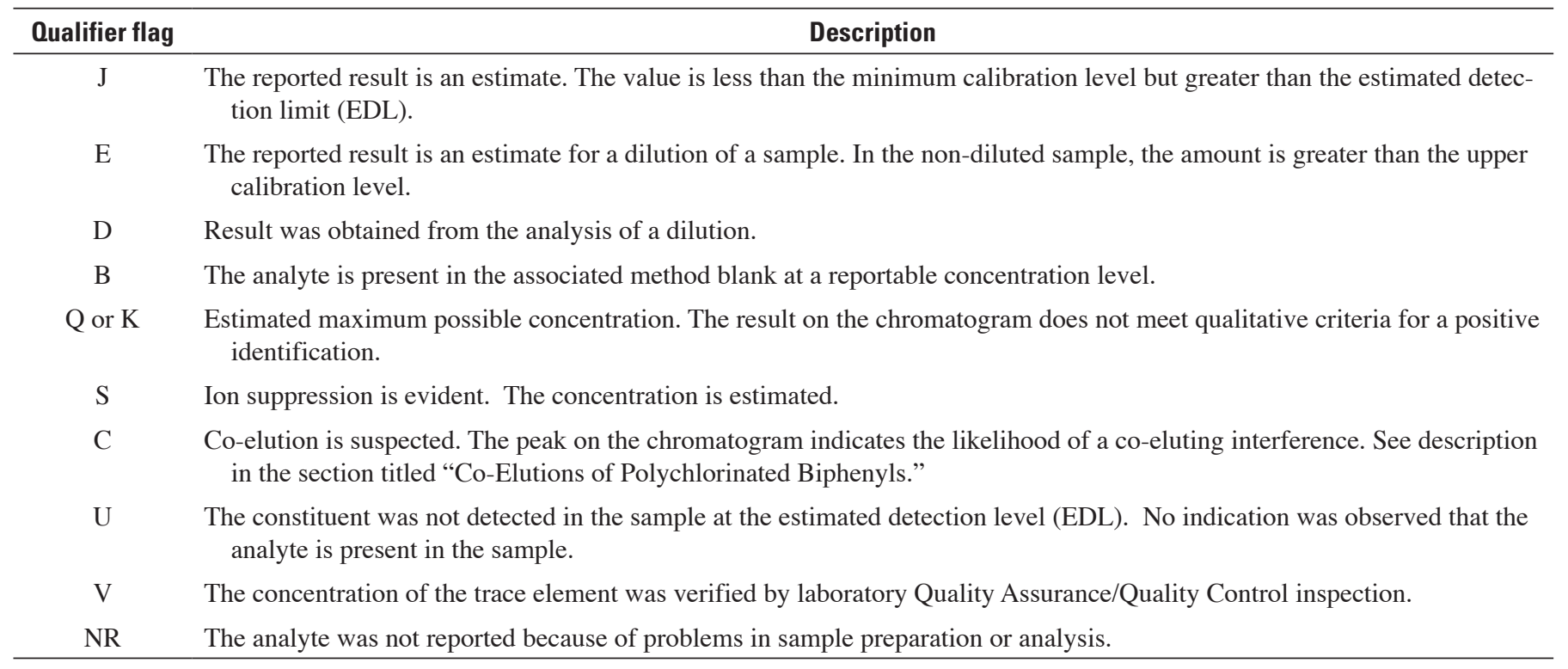


in the field and equipment blanks are listed adjacent to the concentrations in table 19.

\section{Co-elutions of Polychlorinated Biphenyls}

The chromatographic analysis for PCBs was affected by co-elution of several congeners, which made it impossible to uniquely identify them in the sample. An initial study was performed to verify the retention times and elution order for all 209 PCB congeners and to identify the co-eluting congener sets that affect the PCB set used by NJ CARP (table 20). Values for all co-elutions are reported and are flagged with a "C." The lowest numbered congener in a co-elution set is flagged with "C." No value is reported for the higher numbered congeners in the set, but the congeners are flagged with a " $\mathrm{C}$ " followed by the lowest numbered congener in the co-elution set. For example, if $100 \mathrm{pg}$ is detected at the retention time of PCB 26, and PCB 29 co-elutes with PCB 26, then the results are presented as:

PCB $26100 \mathrm{C}$

PCB 29 -- C26

\section{Quality Assurance and Quality Control Samples}

The contract laboratories were required to operate a quality assurance and quality control (QA/QC) program to demonstrate initial precision and other data-quality objectives in addition to the internal proprietary checks that occur as part of the contract laboratory operations. The samples for QA/QC (tables 21 and 22) included Standard Reference Materials (SRMs), which are National Institute of Standards and Testing (NIST) materials that have certified concentrations and are spiked into solids or aqueous matrices. QA/QC samples also included environmental sediment provided as part of the National Institute of Standards and Technology/National Oceanic and Atmospheric Administration program (National Institute of Standards and Technology/National Oceanic and Atmospheric Administration, 1998; 2001). In this program, homogeneous samples of Chesapeake Bay (Sediment IX) and Hudson River bottom sediment (Sediment X and XI) were analyzed. These samples contained unknown constituents and were analyzed in triplicate as part of an interlaboratory analysis program to produce certified concentrations for these materials. In addition to these sediment samples containing unknown concentrations of unknown constituents, samples for performance evaluation (PE) (NIST Sediments 1941a and 1944) were analyzed by the contract laboratory. The results of the QA/QC sample analyses are presented in tables 10 to 12.

A number of other steps were taken to ensure the quality and integrity of the analyses, including (1) the evaluation of the cleanliness of the XAD-2 resin batch before it was packed into the columns, (2) analysis of the field blanks from XADresin columns, GFF filters, and bottles that were opened and handled in the field exactly as samples were and (3) analysis of the equipment blanks from samplers, tubing, and filters. Results for all types of blanks are reported along with the corresponding results of analyses of water and suspended sedi-

Table 19. Ranges of reported estimated detection limits (EDLs) and method detection limits (MDLs) for trace elements and organic compounds in field and equipment blanks.

[ng, nanograms; pg, picograms; L, liters; e, estimated]

\begin{tabular}{llll}
\hline \multicolumn{1}{c}{ Constituent } & \multicolumn{1}{c}{ Phase } & \multicolumn{1}{c}{ Type } & \multicolumn{1}{c}{ Typical range of minimum limits or method detection limits } \\
\hline Polychlorinated biphenyls (PCBs) & Sediment & EDL & 100 to $2,000 \mathrm{pg} / \mathrm{sample}$ \\
Polychlorinated biphenyls (PCBs) & Dissolved & EDL & 10 to $1,000 \mathrm{pg} / \mathrm{sample}$ \\
Pesticides & Sediment & EDL & 0.01 to $4.0 \mathrm{ng} / \mathrm{sample}$ \\
Pesticides & Dissolved & EDL & 0.01 to $11 \mathrm{ng} / \mathrm{sample}$ \\
Polycyclic Aromatic Hydrocarbons (PAHs) & Sediment & EDL & 5 to $10 \mathrm{ng} / \mathrm{L}^{1}$ \\
Polycyclic Aromatic Hydrocarbons (PAHs) & Dissolved & EDL & 1.0 to $45 \mathrm{ng} / \mathrm{L}^{1}$ \\
Dioxin/furans & Sediment & EDL & 3 to $15 \mathrm{pg} / \mathrm{sample}^{2}$ \\
Cadmium & Total and dissolved & eMDL & $1.5 \mathrm{ng} / \mathrm{L}$ \\
Lead & Total and dissolved & eMDL & $1.2 \mathrm{ng} / \mathrm{L}$ \\
Mercury & Total and dissolved & eMDL & $0.02 \mathrm{ng} / \mathrm{L}$ \\
Methyl-mercury & Total and dissolved & eMDL & $0.006 \mathrm{ng} / \mathrm{L}$ \\
\hline
\end{tabular}

${ }^{1}$ Program reporting limits were initially set at $25 \mathrm{ng} / \mathrm{L}$ for dissolved PAH compounds and $12 \mathrm{ng} / \mathrm{sample}$ for particulate PAH compounds. During the program, the lowest calibration standards (EDLs) were adjusted to $12 \mathrm{ng} / \mathrm{L}$ and $12 \mathrm{ng} /$ sample for solids; however, the method was capable of reporting concentrations as small as $0.1 \mathrm{ng} / \mathrm{sample}$ for these compounds.

${ }^{2}$ Dioxin/furans were measured only in sediment. 
Table 20. Description of co-eluting polychlorinated biphenyl congener sets.

[NJ CARP, New Jersey Contaminant Assessment Reduction Program; PCB, Polychlorinated biphenyl; --, not applicable; BZ\#, Ballschmiter and Zell number; the congeners in bold type are those in the subset of PCBs studied in the NJ CARP]

\begin{tabular}{|c|c|c|c|}
\hline $\begin{array}{l}\text { PCB homolog } \\
\text { group }\end{array}$ & $\begin{array}{l}\text { Congener numbers in } \\
\text { the homolog group }\end{array}$ & $\begin{array}{c}\text { Co-eluting congener sets that affect } \\
\text { the NJ CARP data set }{ }^{2}\end{array}$ & $\begin{array}{l}\text { Other known co-eluting congeners } \\
\text { in the chlorination level group }\end{array}$ \\
\hline Mono-CB & $1-3$ & -- & -- \\
\hline Di-CB & $4-15$ & -- & $12 / 13$ \\
\hline Tri-CB & $16-37$ & $\begin{array}{l}\mathbf{2 0 / 3 3} / 21 \\
\mathbf{2 4 / 2 7} \text { (samples after 2/1/02) } \\
\mathbf{2 6} / 29\end{array}$ & -- \\
\hline Tetra-CB & $38-81$ & $\begin{array}{l}\text { 44/62/75; } \\
\text { 40/64; } \\
\text { 70/74/76; } \\
\text { 43/69; 45/51; 47/695; 52/73 }\end{array}$ & $\begin{array}{l}41 / 71 \\
58 / 67\end{array}$ \\
\hline Penta-CB & $82-126$ & $\begin{array}{l}\text { 86/87/97/125; } \\
\text { 83/99; } \\
\text { 90/101/116; } \\
\text { 108 (BZ\# 109)/119; } \\
\text { 95/100; 110/115; 114/122 }\end{array}$ & $\begin{array}{l}\text { 82/107/111/124/108B; 89/121; } \\
98 / 102 \\
116 / 117\end{array}$ \\
\hline Неха-СB & $127-169$ & $\begin{array}{l}147 / 149 \\
135 / 151 / 154 \\
153 / 168 \\
134 / 143 \\
138 / 163\end{array}$ & $\begin{array}{l}129 / 160 \\
139 / 140 \\
146 / 161 \\
150 / 152\end{array}$ \\
\hline Hepta-CB & $170-191$ & $\begin{array}{l}\text { 171/173; } \\
180 / 193\end{array}$ & -- \\
\hline Octa-CB & $192-205$ & $198 / 199 / 201$ & -- \\
\hline Nona-CB & $206-208$ & -- & -- \\
\hline Deca-CB & 209 & -- & -- \\
\hline
\end{tabular}

${ }^{1}$ The range of PCB congeners in each chlorination level, identified by their International Union of Physical and Analytical Chemistry number, is shown in this column.

${ }^{2}$ The known co-elution groups, listed with their lowest PCB congener number first, are listed in this column. Congeners in the subset of PCBs studied for the NJ CARP are in bold type.

${ }^{3}$ Other known co-elution sets that are not reported in the NJ CARP data set are listed in this column.

ment samples in tables 13 to 17 (on CD-ROM at the end of the report.

The results of analyses for SRMs and NIST/NOAA samples are presented in table 12. Results for some SRMs were reported only if they fell outside recovery limits, in which case the laboratory recalibrated the analytical instruments.

\section{Suspended Sediment, Organic Carbon, and Nitrogen}

The field data set also includes the concentrations of SS, POC, and DOC; specific conductance (SC); and concentrations of particulate nitrogen, in the various discrete and composite samples. These data, listed in tables 23 and 24 (on CD at end of report), are used individually or as average values to characterize the water quality of the rivers. These uses are listed below.

1. The geometric mean of the concentrations of the SS, POC, and DOC in samples collected throughout the storm can be used to calculate SS, POC, and DOC loads. For many of the storms, the collection of discrete samples spans the entire length of the storm. Beginning and ending times are listed in table 7.

2. The geometric means of the concentrations of SS, POC, and DOC in discrete samples collected during the time when composite samples were collected by the TOPS and the ISCO \#1 sampler are used to calculate mass of SS and POC either trapped on the GFF filters or contained in the composite trace-element samples. 
Table 21. Description of standard reference materials used in the quality assurance/quality control plan.

[PCB, Polychlorinated biphenyl; PAH, Polycyclic aromatic hydrocarbons; Pb, Lead; Cd, Cadmium; Hg, Mercury; MeHg, Methyl Mercury; SRM, Standard Reference Material; NIST, National Institute of Standards and Technology; NOAA, National Oceanic and Atmospheric Administration]

\begin{tabular}{cccc}
\hline Name & Description of test & Compound class & NIST Standard Reference Materials used \\
\hline SRM \#1 & Periodic check of lowest calibration level standard & $\begin{array}{c}\text { PCBs, pesticides, PAHs, } \\
\text { and dioxin/furans }\end{array}$ & $\begin{array}{c}\text { Laboratory certified standards } \\
\end{array}$
\end{tabular}

SRM \#2 Recovery of SRM solutions spiked onto XAD-resin columns, taken into the field and returned for analysis

SRM \#3 Recovery of SRM solution spiked onto clean silica sand

SRM \#4

Recovery of SRM solution spiked into laboratory water, taken to the field, and returned for analysis
SRM \#5 Recovery of low-level dissolved concentrations of metals in water
NIST/ Composite marine bottom sediment from the Hudson
NOAA River and Chesapeake Bay, along with an SRM sample of marine bottom sediment having a known composition

PCBs and pesticides

PCB: NIST SRM \#2262; Pesticides: SRM \#2261

Dioxin/furans

NIST SRM \#1614

PAHs

NIST SRM \#1491

$\mathrm{Pb}, \mathrm{Cd}$, and $\mathrm{Hg}$

NIST SRM \#1643d (Pb, Cd), NIST 1641d

$(\mathrm{Hg})$, and NRCC DORM-2 (MeHg)
PCBs, pesticides, PAHs, QA97SED7, QA01SEDX, and QAand dioxin/furans $\quad$ 02SEDXI, each analyzed with NIST SRM \#1944
3. To calculate the constituent concentrations in the particulate phase of the sediment collected with the TOPS, the mass of the constituent trapped on the TOPS filters is divided by the mass of SS or POC retained on the filter. During most storms and base-flow events, a single TOPS filter was used for the entire sampling event. The mass of SS on the TOPS filter is, therefore, equal to the mean SS concentration recorded for the event multiplied by the volume pumped through the GFF canister and flat filters, and XAD-resin columns. For some events, however, multiple filters were used and only the first filter was sent to the laboratory for analysis. In these cases, the SS and POC concentrations during the event and during the interval sampled using the TOPS are not the same. Mean concentrations of SS and POC in the samples are reported in tables 23 and 24 for the entire event, the interval of the composite sampling, and the interval of the TOPS sampling for constituents present in the SS. As discussed below, a correction for the efficiency of the TOPS GFF canister filter is applied when calculating the mass of SS retained on the filter.

4. Concentrations of SS, POC, and DOC in the grab samples that were analyzed for trace elements were estimated from the samples collected by the ISCO \#2 sampler nearest to the time the samples for trace elements were collected. The sampling times for the grab samples for trace elements and the corresponding discrete ISCO \#2 samples are indicated in tables 23 and 24.

\section{Field Characteristics}

Several characteristics were measured and recorded in the field during sample collection either manually or with automatic data loggers. These data provide the basic information needed to calculate constituent concentrations from the laboratory-measured contaminant masses. The use of field data facilitates the temporal alignment of the constituent concentrations in water and sediment and the suspended sediment data with the river stage during a storm or base flow.

The field data include dates and times the samples were collected, the river conditions (stage, discharge, and cumulative volume passing the station), characteristics measured with the TOPS (volumes pumped, flow rates), and identification of the various field and equipment blanks associated with each sample. Continuous precipitation amounts were recorded at the National Oceanic and Atmospheric Administration 
Table 22. Summary of quality assurance and quality control analyses.

[SRM, Standard Reference Material; MDL, Method Detection Limits; DCM, Dichloromethane; PCBs, Polychlorinated biphenyls; PAHs, Polycyclic aromatic hydrocarbons; NIST/NOAA, National Institute of Standards and Technology/National Oceanic and Atmospheric Administration]

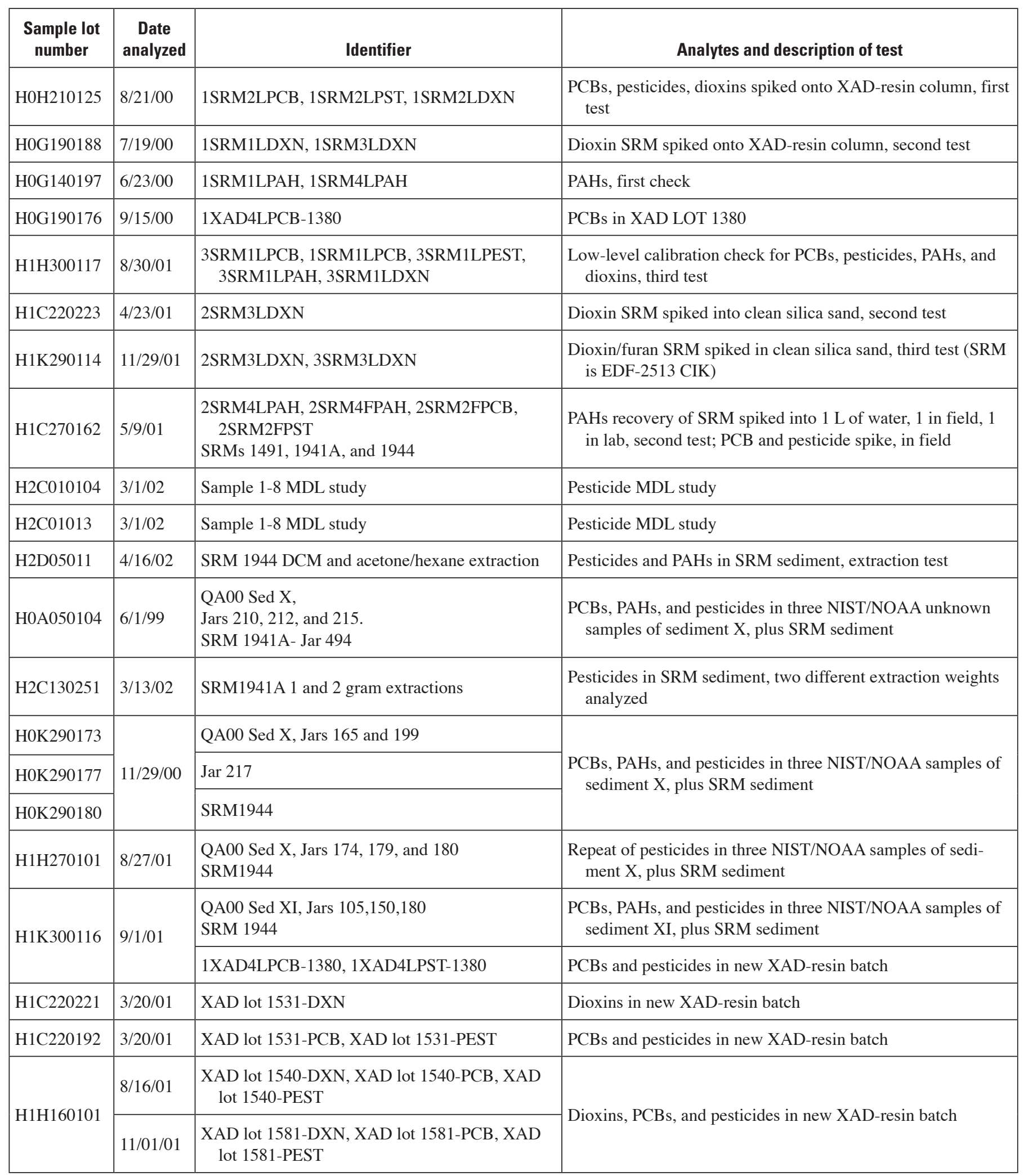


automatic sampling stations (table 25), and continuous stream discharge was recorded at the USGS gaging stations (table 1). Both characteristics were used to assess the magnitude and duration of hydrologic events.

The beginning and ending times of various functions are listed below and with the field data in table 7 . These times were used for some calculations, such as flow rates and loads.

1. The start and end of the hydrologic event (storm or baseflow event), defined as the time when each river's stage began to rise in response to an input of precipitation and the time when conditions returned to near pre-event stage.

2. The start and finish times when composite samples were collected.

3. The start and finish times for use of the filters and XADresin columns that were sent to the laboratory for chemical analysis.

4. The start and finish times when discrete samples for POC, and DOC were collected.

5. The time when the grab samples for trace elements were collected.

Concentrations of SS, DOC, and POC differ depending on the starting and ending times of sample collection. Care was taken to use the correct characteristic value when these data were incorporated with the results of analyses. The reason for more than one concentration for SS, DOC, and POC is that the samples were collected throughout the storm or base-flow event so as to effectively characterize the sediment and organic carbon transported in the river during the sample collection. The total volume of water obtained for the different types of samples was used in three different ways as described below.

1. The total volume of water that passed through the TOPS filters that were sent to a laboratory for analysis was used to calculate sediment-bound constituent concentrations.

2. The total volume of water that passed through the XADresin columns that were sent to a laboratory for analysis was used to calculate constituent concentrations in the dissolved phase.

3. The total volume of water that passed the sampling station during the hydrologic event was used to calculate suspended sediment and other constituent loads for that event.

The field data include the equipment blank sample identification information that matches each equipment blank to its associated TOPS, composite, or grab sample. The data from each equipment blank sample were correlated with the associated sampling media and then used to evaluate the cleanliness of sampling media.
Table 25. Location of precipitation stations in New Jersey river basins.

\begin{tabular}{ll}
\hline \multicolumn{1}{c}{ River basin } & Precipitation station \\
\hline Passaic River & Little Falls \\
Elizabeth and Rahway Rivers & Newark Airport \\
Elizabeth and Rahway Rivers & Canoe Brook \\
Elizabeth and Rahway Rivers & Essex Fells \\
Hackensack River & Woodcliff Lake \\
Raritan River & Bound Brook \\
Raritan River & Somerville \\
Raritan River & Clinton \\
\hline
\end{tabular}

\section{Calculation of Concentrations from Analytical Results}

The analytical results for organic compounds (tables 13 to 17) are recorded as masses of analytes recovered from the SS phase (the analyzed extract from the combined canister and flat filters) and the dissolved phase (the analyzed extract from the two combined XAD-resin columns). Results for composite and grab samples, analyzed for trace elements and dissolved PAHs, and results for samples collected for SS, POC, and DOC are reported as concentrations in $1 \mathrm{~L}$ of water that had the same density as the raw sample. The specific conductance of the samples (tables 23 and 24) indicates that all samples, with the possible exception of the sample from the Hackensack River tidal area (H4), can be considered freshwater.

Information required to convert masses of constituents into concentrations, either per unit volume (liter) of water or unit mass of SS (typically grams), is included in the field data (table 7). The data needed to make the conversions are (1) the volume of raw river water that passed through the canister filter and the associated SS and POC concentrations and (2) the volume of filtered water that passed through the XAD-resin columns and the associated DOC concentrations. Because the canister filter has a trapping efficiency of 90 percent, the constituent concentrations in the dissolved phase, determined using the XAD-resin column technique, would be biased high by the presence of fine-grained sediment that passed through the canister filter and became entrapped in the XAD-resin columns. For this reason, flat filters were installed in the sampling lines immediately before the XAD-resin columns. Additional testing showed that using slow flow rates and processing smaller volumes of water (hence the target of $50 \mathrm{~L}$ through the XAD-resin columns) results in a concentration of $\mathrm{SS}$ in the filtered water entering the columns that is below the level that can be accurately quantified by the laboratory $(<0.5$ $\mathrm{mg} / \mathrm{L}$ ). As a result, the concentrations of SS in the dissolved phase could not be adjusted for the small amount of sediment that may have passed through the flat filter and entered the columns. 
The mass of SS collected on the canister and flat filter also requires adjustment for breakthrough. As stated earlier, the canister filter has a trapping efficiency rating of 90 percent. A further reduction of the mass of sediment trapped on the filters also occurs where the filter outfall is split; 90 percent of the flow goes to waste and 10 percent is directed through the flat filters and columns (fig. 4). Because it was not possible to quantify the mass of sediment that was collected on the flat filter, the assumption was made that the entire mass of sediment that was not captured on the canister filter was sent to waste. The calculated mass of sediment (and organic carbon) on the TOPS filters (canister and flat combined) submitted for analysis was reduced by 10 percent. Therefore, sediment mass calculated from the SS (and from the organic carbon, the POC) concentration and the volume processed, adjusted for a 90 percent trapping efficiency, is a conservative estimate of the amount of sediment captured on the filters. The "corrected" masses of sediment and organic carbon on the filter are listed in table 7 .

\section{Normalized Concentrations}

The dissolved concentrations of constituents recovered in the XAD-resin columns can be calculated using

$$
C_{d}=M_{x a d} / V_{x a d}
$$

$$
\begin{aligned}
& \text { where } \\
& C_{d}=\text { dissolved concentration, in mass per liter } \\
& M_{\text {xad }}=\text { mass of constituent recovered from the } \\
& \mathrm{XAD}-2 \text { resin sample, in ng or } \mathrm{pg} \text {; and } \\
& V_{x a d}=\text { volume of water processed through the } \\
& \text { XAD columns, in liters. }
\end{aligned}
$$

The concentration of organic compounds in the suspended sediment can be calculated using

$$
C_{p}=M_{f} /\left(V_{f} * S S * f * 1000\right)
$$

$$
\begin{aligned}
\text { where } & \\
C_{p}= & \text { concentration in sediment, in mass per } \\
& \text { gram of sediment; } \\
M_{f}= & \text { mass of constituent recovered in the filter } \\
& \text { sample, in pg or ng; } \\
S S \quad= & \text { mean suspended sediment concentration, } \\
& \text { in milligram of sediment per liter; } \\
V_{f}= & \text { volume of water passed through filter; and } \\
f= & \text { filter efficiency, } 0.9 .
\end{aligned}
$$

\section{Particulate Organic Carbon Normalized Concentrations in Sediment}

POC normalized concentrations are calculated using

$$
C_{p c}=M_{f} /\left(V_{f} * P O C * f * 1000\right),
$$

$$
\begin{aligned}
\text { where }_{p c}= & \text { concentration of constituent normalized to } \\
& \text { mass of particulate organic carbon, in mass } \\
& \text { per gram of organic carbon; } \\
M_{f}= & \text { mass of constituent recovered on filter, in } \\
& \text { pg or ng; } \\
V_{f}= & \text { volume of water passed through filter; } \\
P O C= & \text { mean particulate organic carbon content, in } \\
& \text { mg C per liter; and } \\
f \quad= & \text { filter efficiency, } 0.9 .
\end{aligned}
$$

The fraction of particulate organic matter $\left(\mathrm{f}_{\mathrm{om}}\right)$ is calculated using

$$
f_{\text {om }}=(P O C / S S) * 1000,
$$

$$
\begin{aligned}
& \text { where } \\
& f_{\text {om }}=\text { particulate organic carbon content of the } \\
& P O C=\text { mean particulate organic carbon content, in } \\
& \text { mg C per liter; and } \\
& S S=\text { mean suspended sediment concentration, } \\
& \text { in } \mathrm{mg} \text { of sediment per liter. }
\end{aligned}
$$

\section{Concentrations in composite samples}

Analytical results for trace elements and PAHs in composite samples are reported in concentration units of mass per unit volume of water and require no further reduction.

\section{Trace-element concentrations in sediment from grab samples}

Concentrations of trace elements in the particulate phase can be determined as the difference between the total and dissolved trace element concentrations using

$$
p_{M}=\left(t_{M}-d_{M}\right) * 1000 / S S,
$$

$$
\begin{aligned}
\text { where } & \\
p_{M}= & \text { particulate trace element concentration in } \\
& \text { nanograms per liter; } \\
t_{M}= & \text { total trace element concentration in } \\
& \text { nanograms per liter; } \\
d_{M}= & \text { dissolved trace element concentration, in } \\
& \text { nanograms per liter; and } \\
S S \quad= & \text { concentration of suspended sediment in } \\
& \text { milligrams per liter. }
\end{aligned}
$$

Particulate trace element concentrations can be normalized to POC using the fraction of particulate organic matter equation noted above (5). Concentrations of dissolved trace elements are in units of nanograms per liter and can be normalized to DOC. 


\section{Data Evaluation}

\section{Analysis of Standard Reference Materials Results}

The quality-assurance program used in this study included the analysis of SRMs. These analyses provide insight into the accuracy and precision of the analysis of river water and sediment which, in turn, allows limits to be placed on the constituent concentrations measured in the samples from the rivers and on the confidence that can be placed in conclusions made when interpreting the results. These analyses were made throughout the study and provide an indication of the ongoing quality of the analytical methods. In this study, repeated measurements were made for the NIST SRM 1944 for PAHs, PCBs, and pesticides, along with two analyses of SRM 1941a for pesticides. The results of these measurements are listed in tables 26 to 28 .

Accuracy of the measurement of any individual compound can be determined by comparing the measured and certified values. Typically, a measured value can be considered accurate if it is within one to three $\mathrm{Z}$ scores of the certified value, where the $\mathrm{Z}$ score is calculated as:

$$
Z=(x-X) / \sigma,
$$

$$
\begin{aligned}
\text { where } & \\
x & =\text { concentration measured, } \\
X & =\text { mean concentration of multiple } \\
& \text { measurements of the standard, and } \\
\sigma \quad= & \text { target value standard deviation. }
\end{aligned}
$$

The choice of $\sigma$ is dependent upon the data-quality objectives of the particular program (National Institute of Standards and Technology/National Oceanic and Atmospheric Administration, 2001). The $\sigma$ can be fixed or estimated. For some compounds, the results were within one to three $\mathrm{Z}$ scores of the certified value. For other compounds, a wide discrepancy was obtained. The SRM measurements were reviewed by NJDEP as part of CARP.

The precision of the analyses is represented by the standard deviation of the mean of the measured concentrations (tables 26 to 28), which provides an estimate of the analytical uncertainty for each compound or class that was measured. Values for the standard deviation, when converted to a percentage, range from less than 1 percent to slightly greater than 30 percent. The magnitude of this range demonstrates the difficulty in measuring some compounds in natural non-homogeneous materials. For example, the precision of the analyses for PCBs indicates that it is apparently more difficult to accurately analyze lower numbered PCB congeners than higher numbered PCB congeners. This could be the result of increased volatility and presence in the atmosphere (a source of laboratory contamination) of the lower numbered congeners. Some extreme variations occur for the pesticide compounds, both in accuracy and precision of the SRM measurements, which limits the usefulness of the pesticide data set. These variations can be explained by problems associated with the isotope method and the fragmentation of pesticides in the GC column (David Thal, Severn Trent Laboratories, oral commun., 2002). Not all the pesticide compounds are affected by difficulties with accuracy and precision, however, and some of the data can be used with confidence. In general, for most of the compounds, the precision ranged from 5 to 15 percent of the mean, which is similar to uncertainties reported by the contract laboratory for other studies and reported in USEPA methods for environmental analyses (U.S. Environmental Protection Agency, 1999b).

\section{Estimation of Uncertainty in Concentrations}

The magnitude of potential error associated with the data collected in this study is incorporated into the comparisons, the calculation of ratios, and other data-reduction techniques. The error derives from random variations in the analytical and sampling methods. Errors can be summed to provide an estimate of total minimum error using the propagation methods described by Shoemaker and others (1974). No systematic errors are known to have affected the field measurements or reported analytical results; therefore, these types of errors require no further consideration. The following error propagation example demonstrates how the uncertainty associated with any of the constituent concentration data generated in this study can be estimated. The error propagation equations that are used are taken from Shoemaker and others (1974).

Final calculated values (F), such as concentrations normalized to a liter of water or a gram of sediment, are derived from raw data, such as the measured volume of water that was processed or the measured mass of constituent in an XADresin column, or from intermediate values that are calculated from measured values, such as mass of sediment collected on filters. Random error $\left(\lambda_{x, y, z, \ldots}\right)$, associated with each raw or intermediate variable $(\mathrm{x}, \mathrm{y}, \mathrm{z}, \ldots)$, is combined to obtain an error for the final value $\left(\lambda_{\mathrm{F}}\right)$. The calculation made to obtain the final value represents a function for which different forms of error propagation equations exist, depending on the operations in the function. For the commonly incurred function of the form

$$
F=\mathrm{a} x+\mathrm{b} y+\mathrm{c} z+\ldots,
$$

the error propagation equation is

$$
\lambda_{\mathrm{F}}^{2}=\mathrm{a}^{2} \lambda^{2}{ }_{x}+\mathrm{b}^{2} \lambda^{2}{ }_{y}+\mathrm{c}^{2} \lambda_{z}^{2} .
$$

Another common function and its error equation is

$$
\begin{gathered}
F=\operatorname{axyz} \ldots(\text { or } x y z / \mathrm{a}, \operatorname{axy} / z \text { or } \mathrm{a} x / y z \text { or } \mathrm{a} / x y z) \\
\lambda_{\mathrm{F}}^{2} / \mathrm{F}^{2}=\lambda^{2}{ }_{x} / x^{2}+\lambda^{2}{ }_{y} / y^{2}+\lambda^{2}{ }_{z} / z^{2},
\end{gathered}
$$




$$
\begin{aligned}
\text { where } & \\
\mathrm{F} & =\text { the final calculated value of the function; } \\
x, y, z, \ldots & =\text { measured or intermediate variables; } \\
\mathrm{a}, \mathrm{b}, \mathrm{c}, \ldots & =\text { constants values; } \\
\lambda_{(x, y, z)}= & \text { the estimated error for intermediate } \\
& \text { variables } \mathrm{x}, \mathrm{y}, \mathrm{z} ; \text { and } \\
\lambda_{\mathrm{F}} & =\text { the estimated error in the final calculated } \\
& \text { value. }
\end{aligned}
$$

To propagate the random error, each step of the samplecollection and -analysis procedure must be evaluated and the random error assigned to each variable in the procedure. Typically, the error is replaced with a measure such as the variance of replicate analysis or measurements, the tolerance of the glassware, other similar measurements, or best guesses. This can be an involved process, especially for the analytical measurements, because the error is evaluated for each step of the analysis. For example, the random error associated with the reported mass of contaminant includes error introduced by the standards, glassware, balances, syringes, and other analytical equipment, and the error introduced from the standard curve used in the laboratory analysis. Similar consideration applies to the analyses of SS and organic carbon. It is not possible without detailed information on the laboratory procedures to calculate the error associated with the chemical measurements. Laboratories often provide an estimate of the analytical uncertainty; typically, the precision of repeated measurements of SRMs is used as an estimate of error. Several types of fieldmeasured data are required to calculate concentrations. These include the volumes of water pumped through the XAD-resin columns or filters. Each of these data types has an error or uncertainty associated with it.

The following example serves to illustrate the procedures that would be used to estimate a minimum error in the concentration calculated for PCB congener 66 in a water sample collected from the Raritan River on 3/21/02.

\section{Error in the Calculation of Dissolved Concentrations}

The volume of water that passed through the XAD-resin columns or filters was determined by collecting the processed water in carboys and measuring it using a 1-L graduated cylinder with an error of +/- $20 \mathrm{~mL}$. For the Raritan River sample, 31.2 L of water passed through the XAD-resin columns and was measured into 31.2 1-L samples. The volume of water processed and its estimated minimum error is

$$
\begin{gathered}
31.2 \mathrm{~L}=31.2 * 1 \mathrm{~L} \\
\lambda_{\mathrm{F}}^{2}=\mathrm{a}^{2} \lambda^{2}{ }_{x} \\
\lambda_{\mathrm{F}}^{2}=31.22 * 0.022^{*}=0.389 \mathrm{~L} \\
\lambda=0.624 \mathrm{~L}
\end{gathered}
$$

or a relative minimum error of $(0.624 / 31.2) * 100=2$ percent of the total volume.
The mass of PCB \#66 measured in this XAD-2 resin sample was $568 \mathrm{pg}$. Using the standard deviation of the multiple measurements of PCB \#66 in the SRM 1944 (6.7 percent, table 27) as the analytic error, the error in the PCB mass measured in the sample is

$$
38 \mathrm{pg}=568 \mathrm{pg} * 0.067
$$

The error in the concentration of dissolved PCB \#66 is the sum of the analytic error and the error in the volume of water processed:

$$
\begin{gathered}
18.2 \mathrm{pg} / \mathrm{L}=568 \mathrm{pg} / 31.2 \mathrm{~L} \\
\lambda_{\mathrm{F}}^{2} / \mathrm{F}^{2}=\lambda^{2} / x^{2}+\lambda^{2} / y^{2}+\lambda^{2} / z^{2} \\
\lambda_{\mathrm{F}}^{2} / 18.2^{2}=38^{2} / 568^{2}+0.624^{2} / 31.2^{2} \\
\lambda_{\mathrm{F}}^{2} / 18.2^{2}=0.0045+0.0004=0.0049 \\
\lambda_{\mathrm{F}}=(0.0049 * 18.22)^{1 / 2}=1.3 \mathrm{pg} / \mathrm{L}
\end{gathered}
$$

for a relative error of $(1.3 / 18.2) * 100=7$ percent of the reported concentration.

There are two points to be made regarding the error associated with concentrations measured in samples collected by using large-volume sampling methods. First, the error in the measured concentration is the sum of the error in a field measurement (the volume of water collected) and an error in the analytical work (estimated by the variance in the SRM analyses). Accurate measurements made in the field are of the utmost importance in order to minimize the error in the volumes of water processed and to keep the total volume processed through the columns and filters as small as possible so that this error is not magnified by a large volume. Second, the analytical error can vary greatly depending on the chemical species studied. This is shown by the large spread in precision for the SRM analytes (tables 26 to 28). Some pesticides, for example, are difficult to measure precisely and have analytical variances larger than 30 percent (table 28). A QA/QC program that includes multiple measurements of representative SRMs is one reliable method to demonstrate the precision of the analytical measurements.

\section{Error in the Calculation of Constituent Concentrations in the Particulate Phase}

Concentrations of sediment-bound constituents are calculated from the recovered mass of the constituent, the volume of water that passed through the filters, and the SS or POC concentration. The error associated with the particulate-bound constituents is calculated as the sum of the error associated with the analysis of each of these intermediate variables.

The error associated with the analysis for SS is calculated first. A total of 58 discrete samples were analyzed for SS, and a geometric mean concentration of $292.5 \mathrm{mg} / \mathrm{L}$ was calculated. Analysis of SS involves weighing the filter, measuring and filtering the entire collected sample, drying the filtrate, and re-weighing the filter. The USGS Kentucky WSC Labora- 
Table 26. Means and variances for polycyclic aromatic hydrocarbons measured in standard reference materials .

[SRM, Standard Reference Material; NA, Not applicable; PCB, Polychlorinated biphenyl; ng/g, nanogram per gram]

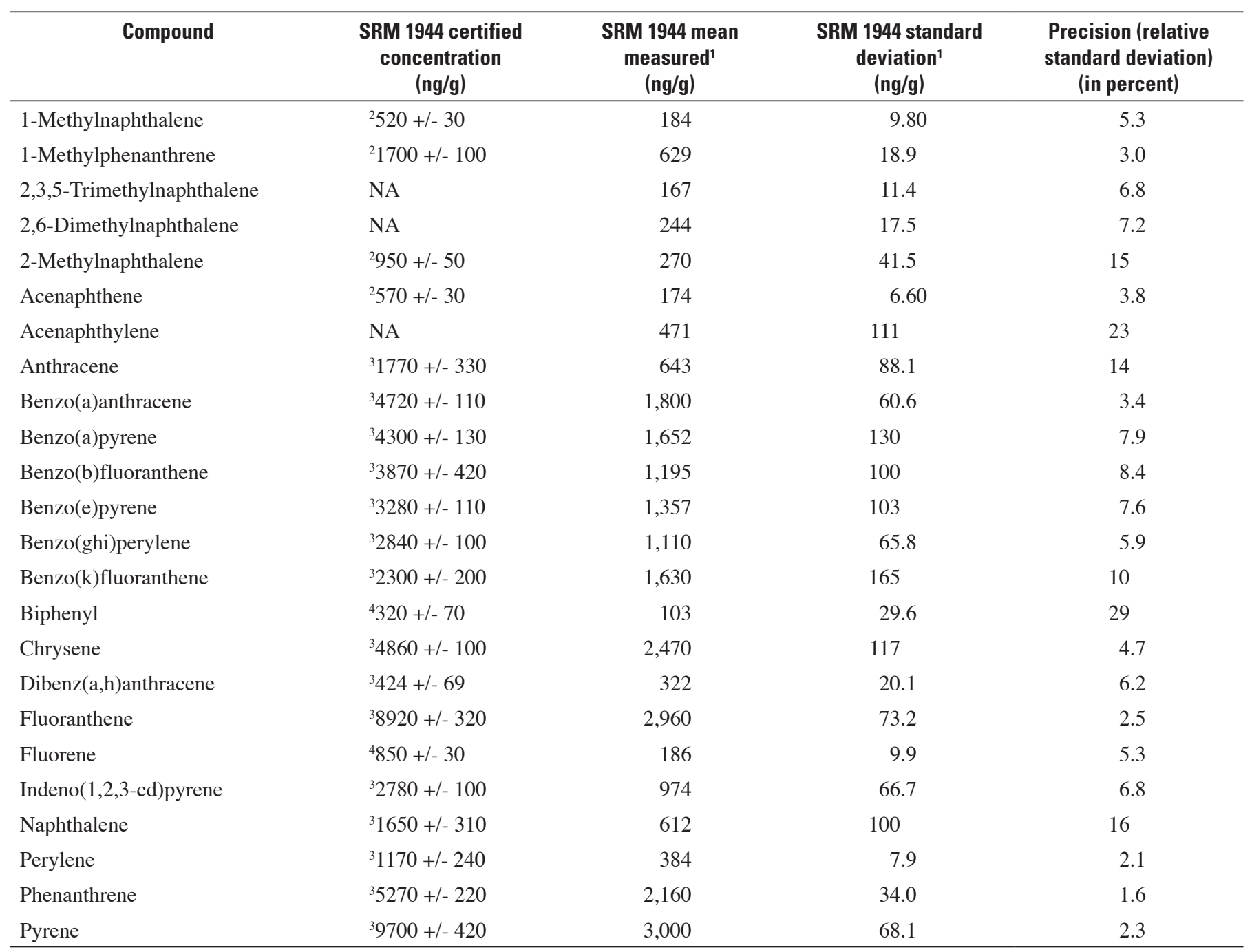

${ }^{1}$ Mean and standard deviation were calculated for four analyses.

${ }^{2}$ Concentration reported but not certified in SRM.

${ }^{3}$ Concentration is certified in SRM.

${ }^{4}$ Measured concentration of PCB could include a co-eluting congener 
Table 27. Means and variances for polychlorinated biphenyls measured in standard reference materials.

[SRM, Standard Reference Material; PCB, Polychlorinated biphenyl; --, not applicable; ng/g nanogram per gram]

\begin{tabular}{|c|c|c|c|c|}
\hline PCB number & $\begin{array}{l}\text { SRM } 1944 \text { certified } \\
\text { concentration, } \\
(\mathrm{ng} / \mathrm{g})\end{array}$ & $\begin{array}{l}\text { SRM } 1944 \text { mean measured } \\
\text { concentration }{ }^{1} \\
(\mathrm{ng} / \mathrm{g})\end{array}$ & $\begin{array}{c}\text { SRM } 1944 \text { measured } \\
\text { standard deviation } \\
(\mathrm{ng} / \mathrm{g})\end{array}$ & $\begin{array}{l}\text { Precision (relative } \\
\text { standard deviation) } \\
\text { (in percent) }\end{array}$ \\
\hline 8 & $222.3+/-2.3$ & 21 & 0 & -- \\
\hline 18 & $251+/-2.6$ & 59.6 & 17.6 & 29 \\
\hline 28 & $280.8+/-2.7$ & 81.6 & 2.1 & 2.5 \\
\hline 31 & $278.7+/-1.6$ & 79.8 & 2.5 & 3.1 \\
\hline $44 / 62 / 75$ & ${ }^{2} 60.2+/-2$ & 48.2 & 5.4 & 11 \\
\hline 49 & $253.0+/-1.7$ & 50.3 & 6.7 & 13 \\
\hline 52 & $279.4+/-2$ & 67.2 & 9.6 & 14 \\
\hline 66 & $271.9+/-4.3$ & 64.0 & 4.3 & 6.7 \\
\hline $95 / 100$ & ${ }^{2} 65+/-8.9$ & 50.7 & 13.2 & 26 \\
\hline $99 / 83$ & $237.5+/-2.4$ & 41.9 & 7.3 & 17 \\
\hline 90/101/113 & $273.4+/-2.5$ & 70.4 & 16.4 & 23 \\
\hline 105 & $224.5+/-1.1$ & 21.7 & .9 & 4.1 \\
\hline 118 & ${ }^{2} 58.0+/-4.3$ & 52.2 & 4.0 & 7.6 \\
\hline 128 & $27.47+/-0.28$ & 9.84 & .4 & 4.1 \\
\hline $138 / 163$ & $2,362.1+/-3.0$ & 58.2 & 4.0 & 6.9 \\
\hline $147 / 149$ & ${ }^{2} 49.7+/-1.2$ & 54.0 & 4.3 & 7.9 \\
\hline $153 / 168$ & $274.0+/-2.9$ & 58.9 & 3.0 & 5.1 \\
\hline 156 & ${ }^{2} 6.52+/-0.66$ & 5.17 & .1 & 1.9 \\
\hline 170 & $2,322.6+/-1.4$ & 14.2 & 1.1 & 7.7 \\
\hline 180/193 & ${ }^{2} 44.3+/-1.2$ & 37.9 & 3.0 & 7.9 \\
\hline 187 & $2,325.1+/-1.0$ & 23.5 & 2.4 & 10 \\
\hline 194 & ${ }^{2} 11.2+/-1.4$ & 9.22 & .1 & 1.1 \\
\hline 195 & ${ }^{2} 3.75+/-0.39$ & 3.63 & .2 & 5.5 \\
\hline 206 & ${ }^{2} 9.21+/-0.51$ & 6.59 & .6 & 9.1 \\
\hline 209 & ${ }^{2} 6.81+/-0.33$ & 5.86 & .2 & 3.4 \\
\hline Average & & & & 9.6 \\
\hline
\end{tabular}

${ }^{1}$ Mean and standard deviation calculated for three analyses.

${ }^{2}$ Concentration is certified in SRM.

${ }^{3}$ Measured concentration of PCB could include a co-eluting congener. 
Table 28. Means and variances for pesticides measured in standard reference materials.

[SRM, Standard Reference Material; PCB, Polychlorinated biphenyl; ng/g, nanogram per gram]

\begin{tabular}{|c|c|c|c|c|c|c|}
\hline Compound & $\begin{array}{c}\text { SRM } 1944 \\
\text { certified } \\
\text { concentration } \\
(\mathrm{ng} / \mathrm{g})\end{array}$ & $\begin{array}{c}\text { SRM } 1941 \\
\text { certified } \\
\text { concentration } \\
(\mathrm{ng} / \mathrm{g})\end{array}$ & $\begin{array}{c}\text { SRM } 1944 \\
\text { Mean } \\
\text { measured } \\
\text { concentration }{ }^{1} \\
(\mathrm{ng} / \mathrm{g})\end{array}$ & $\begin{array}{c}\text { SRM } 1944 \\
\text { Standard } \\
\text { deviation }{ }^{1} \\
\text { (ng/g) }\end{array}$ & $\begin{array}{l}\text { Precision } \\
\text { (relative } \\
\text { standard } \\
\text { deviation, in } \\
\text { percent) }\end{array}$ & $\begin{array}{c}\text { SRM } 1941 \\
\text { Mean measured } \\
\text { concentration } \\
(\mathrm{ng} / \mathrm{g})\end{array}$ \\
\hline 2,4'-DDD & ${ }^{3} 38+/-8$ & NA & 47.8 & 8.1 & 17 & 1.05 \\
\hline 2,4'-DDE & ${ }^{3} 19+/-3$ & $0.653+/-0.058$ & 16.6 & 1.3 & 7.8 & .48 \\
\hline 4,4'-DDD & ${ }^{3} 108+/-16$ & $5.16+/-0.47$ & 109.1 & 13.8 & 13 & 4.97 \\
\hline 4,4'-DDE & ${ }^{3} 86+/-12$ & $6.33+/-0.35$ & 76.0 & 4.6 & 6.0 & 5.56 \\
\hline 4,4'-DDT & ${ }^{4} 119+/-11$ & $1.25+/-0.12$ & 214 & 3.7 & 1.7 & .51 \\
\hline Aldrin & NA & NA & NA & NA & NA & .17 \\
\hline beta-BHC & NA & NA & .3 & .043 & 14 & .03 \\
\hline beta-Endosulfan & NA & NA & 4.5 & .021 & .5 & 2.6 \\
\hline cis-Nonachlor & $33.7+/-0.7$ & NA & 5.5 & 1.9 & 34 & .67 \\
\hline Endrin & NA & NA & NA & NA & NA & NA \\
\hline Endrin aldehyde & NA & NA & NA & NA & NA & NA \\
\hline Endrin ketone & NA & NA & NA & NA & NA & NA \\
\hline gamma-BHC (Lindane) & NA & NA & .153 & .043 & 28 & .06 \\
\hline gamma-Chlordane & ${ }^{3} 8+/-2$ & NA & 25.0 & 2.0 & 8.0 & 1.69 \\
\hline Heptachlor & NA & NA & .1 & NA & NA & NA \\
\hline Endosulfan sulfate & NA & NA & NA & NA & NA & NA \\
\hline Heptachlor epoxide & NA & NA & 1.5 & 1.3 & 60 & .01 \\
\hline Methoxychlor & NA & NA & 140.9 & 15.6 & 14 & .45 \\
\hline
\end{tabular}

${ }^{1}$ Mean and standard deviation were calculated for four analyses.

${ }^{2}$ Mean calculated for two analyses.

${ }^{3}$ Concentration reported but not certified in SRM.

${ }^{4}$ Concentration is certified in SRM. 
tory conducts a yearly performance test and has reported that SS concentrations in the range reported here typically have a precision of $+/-0.5 \mathrm{mg} / \mathrm{L}$. The mean concentration of SS and its associated error is calculated using

$292.5 \mathrm{mg} / \mathrm{L}=$ sum of the individual SS concentrations $/ 58$

$$
\begin{gathered}
\lambda_{\mathrm{F}}^{2}=\mathrm{a}^{2} \lambda^{2}{ }_{x} \\
\lambda_{\mathrm{F}}^{2}=582 * 0.52^{2}=841 \\
\lambda_{\mathrm{F}}=29.0 \mathrm{mg} / \mathrm{L}
\end{gathered}
$$

or a relative uncertainty of $(29.0 / 292.5) * 100=9.9$ percent of the mean SS concentration.

Next, the error associated with the volume of water processed through the filters is calculated. A total volume of $190 \mathrm{~L}$ was processed through the filters for this sample and was measured in 190 1-L increments each with an error of $+/-20 \mathrm{~mL}$. The estimated error in the volume of water filtered is calculated using

$$
\begin{gathered}
190 \mathrm{~L}=190 * 1 \mathrm{~L} \\
\lambda_{\mathrm{F}}^{2}=\mathrm{a}^{2} \lambda^{2}{ }_{x} \\
\lambda_{\mathrm{F}}^{2}=1902 * 0.022=14.44 \\
\lambda_{\mathrm{F}}^{2}=3.8 \mathrm{~L} .
\end{gathered}
$$

The error associated with the measured PCB masses and volume of water filtered is calculated using the equations shown for the constituent concentration in the dissolved phase. For the sample collected from the Raritan River, a total of $13,700 \mathrm{pg}$ of PCB \#66 was recovered. Using the variance in the measured concentration of PCB \#66 in SRM 1944 (6.7 percent) as a surrogate, the error in the mass for this congener is $(13,700 \mathrm{pg} * 0.067)=918 \mathrm{pg}$.

The estimated total error in the particulate phase for the concentration of PCB \#66 is the sum of the analytical error in PCB measurement, the error in the SS concentration, and the error in volume processed through the filters. The error associated with the trapping efficiency (0.9) of the filter cannot be assessed. The calculated concentration and its associated error is

$$
\begin{gathered}
274 \mathrm{pg} / \mathrm{g}=13,700 \mathrm{pg} /(292.5 \mathrm{mg} / \mathrm{L} * 190 \mathrm{~L} * 0.9) \\
\lambda_{\mathrm{F}}^{2} / \mathrm{F}^{2}=\lambda^{2} / x^{2}+\lambda^{2} / y^{2}+\lambda^{2} / z^{2} \\
\lambda_{\mathrm{F}}^{2} / \mathrm{F}^{2}=918^{2} / 13,700^{2}+0.029^{2} / 0.293^{2}+3.8^{2} / 190^{2} \\
\lambda_{\mathrm{F}}^{2} / 2742=0.0045+0.0098+0.0004=0.0147 \\
\lambda_{\mathrm{F}}^{2}=33.2 \mathrm{pg} / \mathrm{g}
\end{gathered}
$$

or a relative error of $(33.2 / 274) * 100=12$ percent. This is roughly twice the error for the analytical measurement based on the variance in SRM measurements.

In evaluating the SS concentrations, it is impossible to know precisely the mass of SS or organic carbon captured on the filters that were analyzed. This was addressed in this study by collecting a sample of the river water for each aliquot collected by the TOPS to obtain the best representative mean value for the SS concentration. Collecting fewer samples dur- ing the storm or base-flow event would increase the uncertainty in the captured SS mass.

\section{Limitations of the Data}

With the exception of the concentrations of trace elements, SS, and organic carbon in the grab samples, the data presented in this report are flow-weighted average concentrations in water and sediment collected during storms. Samples collected during base flow also are considered average compositions because they were collected continuously over a period of several hours during which time streamflow remained steady. The character of these samples and the nature of rivers are noted when using these data, especially when comparing this data to data generated using different sampling techniques. Instantaneous grab samples collected from a river can contain concentrations that differ considerably from the flow-weighted average values produced in this study. The samples collected by the other researchers in the estuary during the storms were large-volume, time integrated grab samples that were collected by sampling continuously over 4 to 6 hours. This difference is noted when integrating the data presented in this work with the data of CARP.

The constituent data collected here are suitable only for evaluating concentrations and loads for the storms or baseflow events during which the rivers were actually sampled. It can be spurious to extrapolate the data from this study, for example, to calculate loads from past or future periods or to calculate loads when flow conditions are higher than those that were actually sampled. This caution arises because it is impossible to unequivocally know that these constituent inputs existed in the past or will exist in the future. The extrapolation to higher flows is also tenuous because of the changes that occur in river characteristics, such as SS content or sources of sediment to a river. The percentage of the total sediment load contributed by fine-grained materials can change considerably during storms because the river velocity is the principal control on the scouring and movement of various sized particles of sediment. During heavy storms, sediment from areas not normally scoured in a river will be mobilized (for example, sediment from higher in the flood plain), and these sediments could contain constituent concentrations or sources of constituents that differ from those observed previously. Because contaminants are most often associated with fine-grained particles (Schwarzenbach and others, 1993) whose abundance in the river water is sensitive to changes in the streamflow velocities, the quantity of particulate-bound contaminant concentrations may be a function of streamflow. Therefore, an average composition prepared from composite samples rather than grab samples is used when studying river chemistry.

An example of how concentrations can vary as a function of discharge, and why it is important to produce accurately composited samples for analysis, is provided by the PCB data from the sample collected during December 2000 from the Passaic River. The mass-normalized particulate-phase concen- 
trations in samples collected from this river during December 2000 were almost 20 times higher than those for other samples collected from this river at other times. The sampling for the December 2000 storm began well after the peaks of streamflow and SS had occurred. Most likely only fine-grained material was present in the river during the receding limb of the hydrograph, when velocities had dropped off and the samples were collected. The December 2000 sample is not an accurate flow-weighted average composition for this storm and more accurately resembles a sample collected during base flow. This example demonstrates the difference between a grab sample that represents a "snap-shot" of the river's chemistry and a composite sample that represents the chemistry over the course of a storm. When grab samples are collected during a storm, the constituent concentrations can vary considerably; therefore, the percentage of fine- and course- grained particulates and the high and low organic carbon content of the particulates that are contained in the sample also vary considerably. These variations can cause substantial differences in computations of constituent concentrations.

\section{Summary}

In an effort to characterize the inputs of contaminants and sediments to Newark and Raritan Bays, water samples were collected from the heads-of-tide on the five tributaries - the Raritan, Passaic, Hackensack, Rahway, and Elizabeth Rivers- that empty into the harbor estuaries. These flow-weighted composite samples were collected during storms of various magnitudes on each of the rivers and during base-flow conditions using a trace organic platform sampler (TOPS) that effectively separated the water into its two phases-- particulate and dissolved constituents. Other samples were collected using automatic samplers. The samples were analyzed for concentrations of suspended sediment, particulate and dissolved organic carbon, trace elements, and organic compounds (polychlorinated biphenyls, polycyclic aromatic hydrocarbons, dioxins/ furans, and pesticides). Samples were collected and analyzed following protocols laid out by the Contaminant Assessment and Reduction Program under the direction of the New Jersey Department of Environmental Protection (NJDEP). Extensive measures were taken to ensure the high quality, precision, and accuracy of the data. These quality-assurance and quality-control procedures are outlined in this document and in the NJDEP Standard Operating Procedures. Many field, trip, and equipment blanks were collected to determine and quantify possible sources of contamination that could have caused biased data results. As part of the quality assurance/quality control (QA/QC) program, some data were received from contract laboratories flagged, indicating areas where further investigation and data reduction were warranted. Another aspect of the QA/QC program included Standard Reference Materials, which are solutions of known compositions that are spiked onto sample-collection media and are used to ensure the quality and integrity of the analyses.

Data received from the laboratories were reported as masses and can be reduced and calculated into concentrations and loads of constituents and sediment using information collected and characteristics measured in the field. All constituent data obtained from analyses of water and sediment samples are raw data. Masses of constituents in the particulate phase can be normalized to sediment and particulate organic carbon. Masses of constituents measured in the dissolved phase can be reduced into concentrations using the volume of water that passed through the XAD-resin columns used in the TOPS. The dissolved concentrations of constituents then can be normalized further to dissolved organic carbon. Further calculations can be executed to estimate various uncertainties that exist within the data and to determine the accuracy and precision of any calculations made using the data. The data on polychlorinated biphenyls, polycyclic aromatic hydrocarbons, dioxins and furans, pesticides, and trace elements presented in this report have myriad uses, such as predicting values of sediment and constituent loads discharged to bays and estuaries over a period of time and identifying possible sources of contamination to the area. Ideally, care is taken when extrapolating the data from a small scale to a broader overall perspective so as to ensure the limitations of the data are recognized and understood. The second phase of this study addresses the interpretation of the raw data.

\section{Acknowledgments}

The authors thank Joel Pecchioli, Gary Buchanan, and Floyd Genichola of the NJDEP for their guidance and direction under the New Jersey Toxics Reduction Program. Mr. Buchanan and Mr. Genichola are especially appreciated for their efforts in bringing ice to the field sites to keep the samples chilled. Scott Douglas of the Marine Resources Division of the New Jersey Department of Transportation is acknowledged for his direction at meetings throughout the duration of the project. The authors are grateful to Dave Thal of Severn Trent Laboratories for sharing his expertise in the analysis of organic compounds. The authors also acknowledge and thank Nicholas Smith and Pamela Jankowski of the USGS for their assistance with sampling. The authors also thank and acknowledge Jessica Hopple and Kara Watson of the USGS for their work using Geographical Information Systems to compile the land-use data presented in this report. 


\section{References Cited}

Ballschmiter, Karlheinz, and Zell, M.G., 1980, Analysis of polychlorinated biphenyls (PCBs) by glass capillary gas chromatography. Composition of Technical Aroclor- and Clophen-PCB Mixtures: Fresenius Zeitschrift fuer Analytische Chemie, v. 302, p. 20-21.

Burkhardt, M.R., Kammer, J.A., Jha, V.K., O.Mara-Lopez, P.G., and M.T. Woodworth, 1997, Methods of analysis by the U.S. Geological Survey National Water Quality Laboratory- Determination of nonpurgeable suspended organic carbon by wet-chemical oxidation and infrared spectrometry: U.S. Geological Survey Open File Report 97-380, 12 p.

Buxton, D.E., Hunchak-Kariouk, Kathryn, and Hickman, R.E., 1998, Relations of surface-water quality to streamflow in the Hackensack, Passaic, Elizabeth, and Rahway River basins, New Jersey, Water Years 1976-93: U.S. Geological Survey Water-Resources Investigations Report 98-4049, $102 \mathrm{p}$.

California Environmental Protection Agency Air Resources Board, 1997, Method 429, Determination of Polycyclic Aromatic Hydrocarbons (PAH) emissions from stationary sources: California Environmental Protection Agency Air Resources Board, 121 p.

National Institute of Standards and Technology/National Oceanic and Atmospheric Administration, 1998, NIST/NOAA NS\&T/EPA EMAP Intercomparison exercise program for organic contaminants in the marine environment: Description and results of 1997 organic intercomparison exercises: NOAA Technical Memorandum NOS ORCA 134, U.S. Department of Commerce, National Oceanic and Atmospheric Administration, Silver Spring, Md., 57 p.

New Jersey Department of Environmental Protection, 2001, New Jersey toxics reduction workplan (NJTRWP) standard operating procedure (SOP) NJTRWP-01, Rev. 1.0, March 2, 2001: New Jersey Department of Environmental Protection, $112 \mathrm{p}$.

New York/ New Jersey Harbor Estuary Program, 1996, Final Comprehensive Conservation and Management Plan: New York/New Jersey Harbor Estuary Program, 122 p.

New York State Department of Environmental Conservation, 1998, Workplan, Sources and loadings of toxic substances to New York harbor: New York Department of Environmental Conservation Division of Water, $17 \mathrm{p}$.
Reed, T.J., White, B.T., Centinaro, G.L., Dudek, J.F., Protz, A.R., Shvanda, J.C., and Watson, A.F., 2004, Water resources data for New Jersey- water year 2003, volume 1. Surface-water data: U.S. Geological Survey Water-Data Report NJ-03-1, 368 p.

Schantz, M.M., Parris, R.M., and Wise, S.A., 2001, NIST Intercomparison exercise program for organic contaminants in the marine environment: Description and results of 2000 organic intercomparison exercises, draft: Gaithersburg, Md., National Institute of Standards and Technology, 26 p.

Schwarzenbach, R.P., Gschwend, P.M., and Imboden, D.M., 1993, Environmental Organic Chemistry: New York, John Wiley and Sons, $681 \mathrm{p}$.

Shoemaker, D.P., Garlan, C.W., and Steinfeld, J.I., 1974, Experiments in Physical Chemistry, (3d ed.): New York, McGraw-Hill, Inc., 725 p.

Sholar, C.J., and Shreve, E.A., 1998, Quality-Assurance Plan for the Analysis of Fluvial Sediment by the Northeastern Region: U.S. Geological Survey Open File Report 98-384, $20 \mathrm{p}$.

Supelco Inc., 2000, Sigma-Aldrich Product information sheet for Amberlite XAD-2 exchange resin: Bellefonte, Pa., 1p.

Thibodeaux, L.J., 1979, Chemodynamics: Environmental Movement of Chemicals in Air, Water, and Soil: New York, John Wiley and Sons, 501p.

U.S. Environmental Protection Agency 1994, USEPA Method 1613: Tetra- through octa- chlorinated dioxins and furans by isotope dilution HRGC/HRMS: U.S. Environmental Protection Agency Office of Water, EPA Report Number EPA/821/ B-94/005, 86 p.

U.S. Environmental Protection Agency, 1996a, USEPA Method 1669: Sampling ambient water for trace metals at EPA water quality criteria levels: U.S. Environmental Protection Agency Office of Water, EPA Report Number EPA-821-R-96-011, 36 p.

U.S. Environmental Protection Agency, 1996b, USEPA Method 1638: Determination of trace elements in ambient waters by inductively coupled plasma-mass spectrometry: U.S. Environmental Protection Agency Office of Water, EPA Report Number EPA/821/R-96-005, 46 p.

U.S. Environmental Protection Agency, 1998a, USEPA Method 8081: Organochlorine pesticides by GC: U.S. Environmental Protection Agency Office of Water, EPA Report Number EPA/SW-846/Ch 4.3.1, 16 p. 
U.S. Environmental Protection Agency, 1998b, USEPA Method 1630: Methyl mercury in water by distillation, aqueous ethylation, purge and trap, cold vapor atomic fluorescence spectrometer: U.S. Environmental Protection Agency Office of Water, EPA Report Number EPA/R/01$020,49 \mathrm{p}$.

U.S. Environmental Protection Agency, 1999a, USEPA Method 1631, Revision B: Mercury in water by oxidation, purge and trap, and cold vapor atomic fluorescence spectrometry: U.S. Environmental Protection Agency Office of Water, EPA Report Number EPA/821/R-99/005, 40 p.

U.S. Environmental Protection Agency, 1999b, USEPA Method 1668, Revision A: Chlorinated biphenyl congeners in water, soil, sediment, and tissues by HRGC/HRMS: U.S. Environmental Protection Agency Office of Water, EPA Report Number EPA-821-R-00-002, 112 p.

Zimmermann, C.F., Keefe, C.W., and J. Bashe, 1997, Method 440.0, Determination of carbon and nitrogen in sediment and particulates of estuarine/coastal waters using elemental analysis: Cincinnati, Ohio, U.S. Environmental Protection Agency National Exposure Research Laboratory, Office of Research and Development, $10 \mathrm{p}$. 
For additional information, write to:

Director

U.S. Geological Survey

New Jersey Water Science Center

Mountain View Office Park

810 Bear Tavern Rd., Suite 206

West Trenton, NJ 08628

or visit our Web site at:

http://nj.usgs.gov/ 


\section{$\frac{1}{4}$}

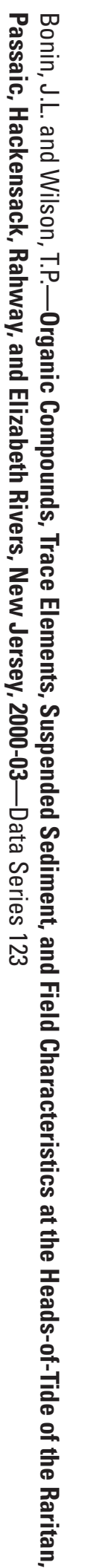

8 Printed on recycled paper 